\title{
Effect of Arthrospira platensis (spirulina) incorporation on the rheological and bioactive properties of gluten-free fresh pasta
}

\author{
Patrícia Fradinho $^{\mathrm{a}, *}$, Alberto Niccolai ${ }^{\mathrm{b}}$, Rita Soares ${ }^{\mathrm{a}}$, Liliana Rodolfi ${ }^{\mathrm{b}, \mathrm{c}}$, Natascia Biondi ${ }^{\mathrm{b}}$, \\ Mario R. Tredici ${ }^{\mathrm{b}, \mathrm{c}}$, Isabel Sousa ${ }^{\mathrm{a}}$, Anabela Raymundo ${ }^{\mathrm{a}}$ \\ ${ }^{a}$ LEAF-Linking Landscape, Environment, Agriculture and Food, Instituto Superior de Agronomia, Universidade de Lisboa, Tapada da Ajuda, 1349-017 Lisboa, Portugal \\ ${ }^{\mathrm{b}}$ Department of Agriculture, Food, Environment and Forestry (DAGRI), University of Florence, Piazzale delle Cascine 24, 50144 Florence, Italy \\ ${ }^{\mathrm{c}}$ Fotosintetica \& Microbiologica S.r.l., Via dei Della Robbia 54, 50132 Florence, Italy
}

\section{A R T I C L E I N F O}

\section{Keywords:}

Spirulina

Psyllium

Digestibility

Antioxidants

Functional foods

Rheology

\begin{abstract}
A B S T R A C T
Gluten-free foods are generally nutritionally deficient and are the source of serious technological constraints. This work aimed to evaluate the technological performance of addition of two spirulina biomasses: Arthrospira platensis F\&M-C256 and Ox Nature (resulting from different drying procedures) to gluten-free pastas, in terms of mechanical properties, antioxidant capacity, in vitro digestibility and sensory analysis.

Texture properties of GF pasta was not significantly $(\mathrm{p}<0.05)$ altered by the incorporation of $A$. platensis biomass. The different drying methods applied to A. platensis biomasses had an impact on the bioactive compounds and the in vitro digestibility of the gluten-free pastas. Both A. platensis biomasses provided a significant $(\mathrm{p}<0.05)$ supplementation of phenolic compounds, chlorophylls and carotenoids to the gluten-free pastas, that resulted in significantly $(\mathrm{p}<0.05$ ) higher antioxidant activity when compared to control (without $A$. platensis) and wheat pasta. Between the new gluten-free developed pastas, consumers preferred the one supplemented with $2 \%$ A. platensis F\&M-C256 biomass. Knowing the contribution of A. platensis biomass addition on pasta properties is fundamental to extend the utilization of this cyanobacterium for novel foods development. These results indicate that $A$. platensis biomass is a suitable ingredient to enhance the nutritional quality of pasta, without affecting its cooking and texture quality properties, with a favourable sensory evaluation.
\end{abstract}

\section{Introduction}

Pasta, traditionally produced with durum wheat semolina, is a widely consumed food product, due to its palatability, low cost and easy preparation. Although dry pasta market represents most of the world's pasta consumption, fresh pasta market share is continuously growing, associated with the consumer's subconscious belief in the close relationship between freshness and artisanal production [1]. Fresh pasta is a recognized vehicle for food fortification (e.g., fibre, vegetables, pulses and microalgae) and has received much attention from the scientific community $[2,3]$.

Gluten-free (GF) product development presents major challenges for the food industry in terms of organoleptic, technological and nutritional characteristics. The GF food market is continuously growing, with estimated market share sales worldwide of $18 \%$ gluten-free pasta in 2022 , with an annual growth rate of 7.4\% [4]. Nowadays, target audience for GF foods stretches beyond coeliac sufferers. In 2015, only $9 \%$ of US gluten-free consumers followed a GF diet due to a celiac disease, while others were adopting a GF lifestyle because it made them feel healthier $(12 \%)$ or wanted to lose weight $(7 \%)$ [5].

In response to consumer's needs, more and more gluten-free products, such as pasta, have appeared on the market. However, these products often do not satisfy the nutritional deficiencies of these consumers in terms of dietary fibre, vitamins (B12, D), and minerals (iron, calcium, zinc) [6]. However, consumers consider GF diet hard to follow due to low availability, lack of variety, texture problems, poor palatability and high prices of the GF products [7].

Psyllium husk is a functional ingredient with a health claim approved by FDA [8] for reducing the risk of coronary heart disease. Underlying this approval is Psyllium's high soluble fibre content that translates into high water absorption and gelling ability, making it possible to use Psyllium as a structure builder that mimics the gluten matrix [9]. Our research group has already explored Psyllium technological functionality in the production of biscuits [10]. In this work we intend to take advantage of both of Psyllium's mentioned features in order to develop a GF functional pasta.

\footnotetext{
* Corresponding author.

E-mail address: pfradinho@isa.ulisboa.pt (P. Fradinho).
} 
Microalgae (including cyanobacteria) are generally recognized as a source of bioactive compounds and their use as nutritional supplements is becoming widely spread in western countries [11]. However, the use of microalgae biomass for incorporation in food products is still limited $[12,13]$. This results from the European gastronomy tradition missing this type of ingredients and also from the regulation restrictions - only a few species approved by EFSA for human consumption [14].

Microalgae comprise a vast array of bioactive compounds with known antioxidant capacity, such as carotenoids, phycobiliproteins or phenolic compounds [15]. So, microalgae have the potential to be used as natural sources of antioxidants. The therapeutic properties of TPC include anticancer, antioxidative, antibacterial, anti-allergic, anti-diabetes, anti-aging, anti-inflammatory and anti-HIV activities [16].

Arthrospira platensis (commonly known as spirulina) represents a valuable source of bioactive compounds and acts as a pigment agent. $A$. platensis is known for its high protein content, as well as $\gamma$-linolenic acid and phycocyanin contents [17]. Our research group has already successfully incorporated spirulina in wheat pasta [18] and, recently, a study with cookies showed that $A$. platensis biomass provided a significant structuring effect, in terms of texture, probably due to its high protein content (around 68\% on dry biomass) [19].

Knowing the microalgae physicochemical characteristics is fundamental for the selection of the most suitable biomass to specific food technology applications and consequently successful novel foods development [20]. The content of the main biochemical components varies depending on the microalga as well as, to a large extent, on the culture conditions such as culture density, growth phase and physiological status [21,22].

Microalgae biomasses can differ greatly in their quality, colour, consistency, and nutrient content [20,23]. The different microalgae biochemical compositions can affect physical and sensorial aspects of the biomass $[20,23]$ and of microalgae-based products such as for food gels, cookies, crackers, and pasta $[3,18,19,24,25]$. In particular, in the study of Fradique et al. [18] a significant difference in protein and carbohydrate contents after cooking, between pasta incorporated with Spirulina maxima biomass and pasta with Chlorella vulgaris biomass (at $2 \%$ incorporation level), was found. In a successive work, Fradique et al. [3] also showed significant differences for all the detected parameters in sensory evaluation (especially colour, depreciative fish flavour and global appreciation) between cooked fresh pasta incorporated with Isochrysis galbana biomass and pasta with Diacronema vlkianum biomass (at $2 \%$ incorporation level), confirming that the different microalgae chemical composition can strongly affect sensory aspects. In a recent work, Batista et al. [19] found a significant difference in protein and phenolic contents between cookies incorporated with $A$. platensis $\mathrm{F}$ \&M-C256, C. vulgaris Allma, Tetraselmis suecica F\&M-M33 and Phaeodactylum tricornutum F\&M-M40 biomasses (at 6\% incorporation level). Besides, A. platensis F\&M-C256 also provided a structuring effect in terms of cookies texture. Batista et al. [25] also found that different microalgae biomasses (A. platensis F\&M-C256, C. vulgaris Allma, T. suecica F\&M-M33 and P. tricornutum F\&M-M40, at $2 \%$ incorporation level) strongly affected sensory aspects of cookies, in particular smell, taste and global appreciation. When microalgae are integrated into foodstuffs, the aroma is an important aspect to consider. The presence of sulfuric compounds, diketones, $\alpha$-ionone, and $\beta$-ionone in fresh microalga biomasses is explained by aroma formation mechanisms such as enzymatic lipid oxidation, enzymatic and chemical degradation of dimethyl sulfoniopropionate (generating dimethyl sulfide), phenylalanine (generating benzaldehyde), and carotenoids (generating ionones) [26]. Studies aimed to mitigate the taste and the smell of microalgae-based products, such as the addition of natural flavours, and to modify the colour, such as extrusion procedures, could be useful techniques to improve the appearance and the taste of these products and therefore to make them more accepted by consumers. Microalgae can also be manipulated to have high protein, high carbohydrate or high lipid content as required $[27,28]$. Customizing microalgae cultivation in order to obtain specific compositions can be of interest for the development of functional GF foods, in order to fulfil the needs of the target population.

The aim of this work was to develop a new A. platensis-based GF fresh pasta and to evaluate the addition of this cyanobacterial biomass as an innovative ingredient in order to enhance the functional properties of pasta. Two strains of $A$. platensis with different chemical composition were used in order to assess its impact on the bioactive compound's evaluation and mechanical features of the final product.

\section{Materials and methods}

\subsection{Microalgae and other ingredients}

Arthrospira platensis F\&M-C256 biomass was provided by Società Agricola Serenissima (Italy). It was cultivated in GWP ${ }^{\circledR}$-I [29] or GWP ${ }^{\circledR}$ II photobioreactors $[30,31]$ in semi-batch mode, in Zarrouk medium [32]. The biomass was collected by centrifugation; washed with tap water to remove excess bicarbonate; frozen $\left(-20{ }^{\circ} \mathrm{C}\right)$; lyophilized; powdered and stored at $-20{ }^{\circ} \mathrm{C}$ until analysis and use. For comparative purposes a spray-dried commercial biological Arthrospira platensis (lot O.SP-JY-170615, Ox Nature, China) was also used. Psyllium husk (lot 047058-02, Solgar, USA), rice flour (lot 3411/18, Ceifeira, Dacsa Atlantic, Portugal) and wheat semolina (lot 20180725 Próvida, Portugal) were purchased in local market (Table 1).

\subsection{Pasta preparation}

Three batches of $200 \mathrm{~g}$ of pasta dough were prepared, using rice flour and Psyllium gel in a 50/50 ratio (control). The ingredients were mixed in a food processor (Bimby TM31, Vorwerk, Wuppertal, Germany), for 3 min (speed 4) at room temperature. Then, the dough was covered in aluminium foil and allowed to equilibrate for $15 \mathrm{~min}$ at $25{ }^{\circ} \mathrm{C}$ in an air oven. Then, the dough was sheeted and laminated as tagliatelle (width $=6.10 \mathrm{~mm}$, thickness $=2.12 \mathrm{~mm}$, length $=10 \mathrm{~cm}$ ) using a benchtop pasta machine (Atlas 150 Wellness, Marcato, Italy).

Arthrospira platensis F\&M-C256 biomass and Ox Nature (from 1 to

Table 1

Biochemical composition of the both A. platensis used in the experiments and of Psyllium, rice flour and wheat semolina.

\begin{tabular}{|c|c|c|c|c|c|c|c|c|c|}
\hline & Protein & Carbohydrate & Lipid & Ash & Total fibre & $\mathrm{Cd}$ & $\mathrm{Pb}$ & As & $\mathrm{Hg}$ \\
\hline A. platensis F\&M-C256 [19] & $68.9 \pm 1.0$ & $12.8 \pm 0.2$ & $10.7 \pm 0.6$ & $6.1 \pm 0.1$ & - & $<0.02^{\mathrm{a}}$ & $<0.10^{\mathrm{a}}$ & $<0.06^{\mathrm{a}}$ & $<0.1^{\mathrm{a}}$ \\
\hline Psyllium [10] & $1.6 \pm 0.1$ & - & $1.1 \pm 0.0$ & $2.6 \pm 0.1$ & $81.7 \pm 6.6$ & - & - & - & - \\
\hline Rice Flour [33] & $7.9 \pm 0.1$ & 90.7 & $0.8 \pm 0.1$ & $0.4 \pm 0.0$ & - & - & - & - & - \\
\hline Wheat semolina ${ }^{b}$ & 12.7 & 73 & 1.1 & - & 3.9 & _- & - & _- & _- \\
\hline
\end{tabular}

Results are expressed as mean $\pm \mathrm{SD}, \mathrm{n}=3$.

* Heavy metal values below the detection threshold of the equipment.

${ }^{\dagger}$ Label information 


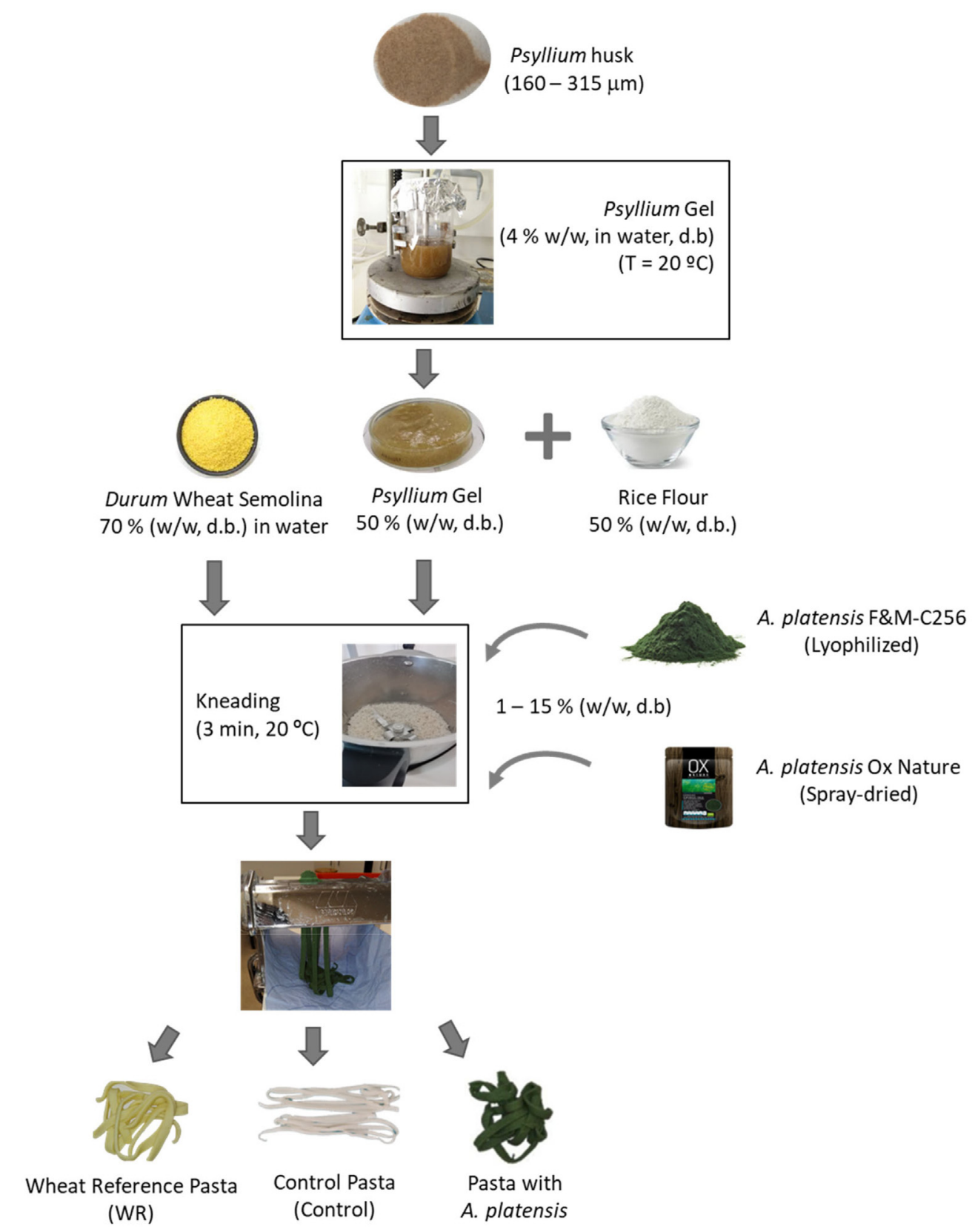

Fig. 1. Schematic representation of the experimental design for the preparation of the samples.

$15 \% \mathrm{w} / \mathrm{w}$ ) were incorporated in rice pasta dough, by replacing rice flour, in order to provide high levels of phytochemicals with bioactive activity. The incorporation limit was set by the impossibility of mixing the ingredients and properly kneading the dough. Since fresh pasta is traditionally prepared with wheat semolina, a wheat reference (WR) pasta, as described by Fradique et al. [18] with commercial durum semolina and water, was prepared for comparison (Fig. 1). Pasta samples were cooked at optimal cooking time, lyophilized and crushed into powder in a pestle and mortar, to be used for biochemical composition determinations, antioxidant activity and in vitro digestibility analyses. Physical analyses (colour, texture and rheology) were performed in the pasta preparation day.

\subsection{Pasta analyses}

\subsubsection{Cooking quality evaluation of pasta}

The tagliatelle samples were cooked in boiling distilled water for
$1 \mathrm{~min}$, and the cooking quality parameters were determined as reported by Fradinho et al. [33]. At least three measurements were performed for each analysis.

\subsubsection{Colour analysis}

The colour of raw and cooked samples was instrumentally measured using a Minolta CR-400 (Japan) colorimeter with standard illuminant D65 and a visual angle of $2^{\circ}$. The results were expressed according to CIELAB system colour parameters $\left(\mathrm{L}^{*}, \mathrm{a}^{*}\right.$ and $\left.\mathrm{b}^{*}\right)$, where $\mathrm{L}^{*}$ defines lightness (values increase from 0 to 100 ), $a^{*}$ measures the degree of redness or greenness (60 to -60 positive to negative values, respectively), and b* the degree of yellowness or blueness (60 to -60 positive to negative values, respectively). The total colour difference between raw and cooked samples, was determined according to Eq. (1).

$$
\Delta \mathrm{E}^{*}=\left[\left(\Delta \mathrm{L}^{*}\right)^{2}+\left(\Delta \mathrm{a}^{*}\right)^{2}+\left(\Delta \mathrm{b}^{*}\right)^{2}\right]^{1 / 2}
$$

The measurements were conducted under the same light conditions, 
using a white standard $\left(\mathrm{L}^{*}=94.61, \mathrm{a}^{*}=-0.53, \mathrm{~b}^{*}=3.62\right)$, under artificial fluorescent light at $20 \pm 1{ }^{\circ} \mathrm{C}$, replicated at least eight times for each sample.

\subsubsection{Rheology measurements}

After pasta dough preparation, each sample (A. platensis enriched; control; WR) was placed into the bottom plate of a $20 \mathrm{~mm}$ serrated parallel plate sensor (PP20) on the rheometer (MARS III, Haake, Karlsruhe, Germany). The temperature control was performed using an UTC-Peltier system and the gap was set at $2 \mathrm{~mm}$. Edges of samples were coated with liquid paraffin, to prevent moisture losses during tests.

Stress sweep tests were conducted at $20^{\circ} \mathrm{C}$ on the samples, to ensure that all measurements were carried out within the viscoelastic region. Frequency sweep tests were performed inside this region from 0.01 to $100 \mathrm{~Hz}$, at $20 \pm 0.5{ }^{\circ} \mathrm{C}$. Each formulation was tested at least in triplicate. Experimental storage (elastic) - $G^{\prime}$ and loss (viscous) - $G^{\prime \prime}$ moduli (Pa) data versus frequency - $\mathrm{f}(\mathrm{Hz})$ were fitted using power models [34], where $\alpha^{\prime}, \alpha^{\prime \prime}, b^{\prime}$ and $b^{\prime \prime}$ are the corresponding fitting parameters (Eqs. (2) and (3)).

$\mathrm{G}^{\prime}(\mathrm{f})=\alpha^{\prime} \mathrm{f}^{\mathrm{b}^{\prime}}$

$G^{\prime \prime}(f)=\alpha^{\prime \prime} f^{b^{\prime \prime}}$

\subsubsection{Texture analysis}

Pasta texture was measured using a texturometer TA.XTplus (Stable MicroSystems, Godalming, UK) with a $5 \mathrm{~kg}$ load cell in a $20{ }^{\circ} \mathrm{C}$ controlled temperature room. Before each test, pasta samples were cooked in boiling water during the respective optimal cooking time, rinsed with distilled water and drained. Three types of texture measurements were preformed:

a) Cutting: the firmness of cooked pasta samples was measured following AACC method 66-50.01 [35]. Pasta firmness was determined by measuring the cutting force required to cut three cooked tagliatelle strips using a blade set with guillotine (HDP/BSG) that cut the sample at $0.17 \mathrm{~mm} / \mathrm{s}$. From this test, adhesiveness (- N.s), which is the resistance of the material when the probe is recessing, was also measured. The thickness of the samples was measured to determine the cutting distance for each sample: 1.8-2.1 mm. Each formulation was replicated at least eight times.

b) Stickiness: pasta stickiness is defined as the maximum peak force required to separate the probe from the sample surface (peak height) and the area under the peak represents the work of adhesion. To study the adhesive properties is imperative to have a procedure that forces a clean separation at the probe-material interface [36]. Three tagliatelle strips were centrally aligned under a circular plexiglass probe (44 $\mathrm{mm}$ diameter) on a raised platform and were retained within a circular slot ( $48 \mathrm{~mm}$ diameter) made in a base plate. The samples were compressed for $2 \mathrm{~s}$ with an applied force of $9.807 \mathrm{~N}$ at $0.5 \mathrm{~mm} / \mathrm{s}$. At least ten replicates were performed of each pasta formulation. The precision of the stickiness measurement decreases as elapsed time increases. Therefore, the time for stickiness measurements was set at 15 min after draining.

c) Extensibility: cooked pasta extensibility characteristics were determined using a Kieffer Dough \& Gluten Extensibility Rig (A/KIE). Sample loading and test were conducted as follows: a tagliatelle strip was placed across the grooved region on the sample plate. The hook probe was positioned under the strip and then raised upward at $2.0 \mathrm{~mm} / \mathrm{s}$, stretching the strip until rupture. From this tension test 2 parameters were obtained: the maximum resistance to extension (Rmax, N) and the extensibility until rupture (ERmax, mm).

\subsubsection{Proximate chemical composition, chlorophylls and carotenoids determination \\ Crude protein and lipid content were determined following Lowry}

et al. [37] and Marsh and Weinstein [38], respectively. Carbohydrate was determined following Dubois et al. [39]. Moisture and ash were analysed following ISTISAN protocols (ISTISAN Report 1996/34, method B, page 7 and ISTISAN Report 1996/34, pages 77-78, respectively). Chlorophylls and carotenoids were determined following Jeffrey and Humphrey [40].

Heavy metal determinations were performed in an external lab by Atomic Absorption Spectrometry with Hydride Generation (Cd and $\mathrm{Pb}$ ), Atomic Absorption Spectrometry with Graphite Furnace (Hg), and Inductively Coupled Plasma Optical Emission Spectrometry (As).

All chemical composition analyses were repeated, at least in triplicate, and were performed on lyophilised cooked pasta.

\subsubsection{Phenolics and antioxidant capacity determination}

The total phenolic content assay was carried out according to Ganesan et al. [41] using the Folin Ciocalteu assay. Samples of $0.1 \mathrm{~g}$ of cooked pasta were dissolved in $6 \mathrm{~mL}$ of deionised water and sonicated for $30 \mathrm{~min}$ at the maximum power (frequency $20 \mathrm{kHz}$, power $130 \mathrm{~W}$ ) maintaining the temperature below $30{ }^{\circ} \mathrm{C}$ by immerging the sample flask in an ice bath (MicrosonTM XL2000, Misonix Inc., Farmingdale, New York, USA). To $100 \mu \mathrm{L}$ aliquots of each samples, $2 \mathrm{~mL}$ of $2 \%$ sodium carbonate (Sigma-Aldrich) in water were added. After $2 \mathrm{~min}$, $100 \mu \mathrm{L}$ of $50 \%$ Folin Ciocalteu reagent (Sigma-Aldrich) was added. The reaction mixture was incubated in darkness at $25{ }^{\circ} \mathrm{C}$ for $30 \mathrm{~min}$. The absorbance of each sample was measured at $720 \mathrm{~nm}$. Results were ex-

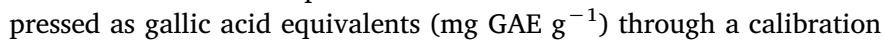
curve with gallic acid (0 to $150 \mu \mathrm{g} \mathrm{mL}^{-1}, \mathrm{R}^{2}=0.9907$ ) (Sigma-Aldrich).

To evaluate the radical scavenging capacity of the cooked pasta samples, the 2,2-diphenyl-1-picrylhydrazyl (DPPH) radical scavenging assay was carried out according to Rajauria et al. [42]. Briefly, the assay was performed in 96-well microtiter plates (Greiner Bio-One International GmbH, Germany) with $100 \mu \mathrm{L}$ of DPPH radical solution $(165 \mu \mathrm{M}$, in methanol, Sigma-Aldrich) and $100 \mu \mathrm{L}$ of sample ( $0.2 \mathrm{~g}$ of lyophilised cooked pasta samples extracted for $30 \mathrm{~min}$ in $5 \mathrm{~mL}$ of a 1:5 methanol:water solution). The reaction mixtures were incubated in darkness at $30{ }^{\circ} \mathrm{C}$ for $30 \mathrm{~min}$. The absorbances were measured at $517 \mathrm{~nm}$ using a UV-Vis spectrophotometric plate reader (BioTek USA). The antioxidant capacity of the samples was expressed in terms of $\mu \mathrm{g}$ of Vitamin $\mathrm{C}$ Equivalent Antioxidant Capacity (VCEAC) per gram of sample (ascorbic acid calibration curve: 0 to $10 \mathrm{mg} \mathrm{mL}^{-1}, \mathrm{R}^{2}=0.992$ ) and corresponding Radical Scavenging Activity (RSA). Two blank assays, one without sample and the other without reagents were also performed. Analyses were repeated in triplicate and performed in cooked pasta samples, previously lyophilized.

\subsubsection{In vitro digestibility tests}

The cooked pasta samples in vitro digestibility (IVD) was assessed by the Boisen and Fernández [43] method. Cooked pasta samples were weighed ( $1 \mathrm{~g}$, particle size $\leq 1 \mathrm{~mm}$ ) and transferred to $250 \mathrm{~mL}$ conical flasks. To each flask, phosphate buffer $(25 \mathrm{~mL}, 0.1 \mathrm{M}, \mathrm{pH} 6.0)$ was added and mixed, followed by $\mathrm{HCl}(10 \mathrm{~mL}, 0.2 \mathrm{M})$ and $\mathrm{pH}$ was adjusted to 2.0. A freshly prepared pepsin water solution (3 mL; Applichem, Darmstadt, Germany) containing $30 \mathrm{mg}$ of porcine pepsin (0.8 FIP-U/ $\mathrm{mg}$ ) was added. The flasks were incubated at $39^{\circ} \mathrm{C}$ for $6 \mathrm{~h}$ with constant agitation (150 rpm). After, phosphate buffer (10 mL, $0.2 \mathrm{M}, \mathrm{pH} 6.8)$ and $\mathrm{NaOH}$ solution $(5 \mathrm{~mL}, 0.6 \mathrm{M})$ were added to each sample, and $\mathrm{pH}$ was adjusted to 6.8. A freshly prepared pancreatin ethanol:water solution $(10 \mathrm{~mL}, 50: 50 \mathrm{v} / \mathrm{v})$ containing $500 \mathrm{mg}$ of porcine pancreatin (42362 FIP-U/g, Applichem, Darmstdat, Germany) was added to each sample. The flasks were incubated again at $39{ }^{\circ} \mathrm{C}, 150 \mathrm{rpm}$, for $18 \mathrm{~h}$. A reagent blank without sample was also prepared. The undigested residues were collected by centrifugation at $18,000 \times g$ for $30 \mathrm{~min}$ and washed with deionised water. This procedure was repeated twice, and the final supernatant was filtered on glass-fibre membranes $(47 \mathrm{~mm} \varnothing$, pore $1.2 \mu \mathrm{m})$. The pellet and membranes were dried at $80{ }^{\circ} \mathrm{C}$ for $6 \mathrm{~h}$, and 
then at $45{ }^{\circ} \mathrm{C}$ until constant weight.

The dry matter (DM), crude protein (CP), and carbohydrate (C) in vitro digestibility (\%) of all pasta samples was calculated from the difference between the initial biomass and the undigested biomass (after correction for the blank assay) divided by the initial biomass and multiplied by 100. Casein (Sigma Aldrich Corp., St. Louis, USA) was used as the reference material with $100 \%$ digestibility. Analyses were repeated in triplicate.

\subsubsection{Sensory analysis}

Sensory analysis assays were performed for gluten-free pasta with both $A$. platensis biomasses, studied at $2 \%$ incorporation level, and with the control pasta. The assays were conducted in a standardized sensory analysis room. Each pasta formulation was prepared and cooked according to the procedure described earlier and served immediately. An untrained panel of 31 individuals, 10 males and 21 females, with ages between 20 and 60 , evaluated the cooked pasta samples, in terms of colour, odour, flavour, extensibility, texture and global appreciation according to 5 levels from "very unpleasant" to "very pleasant". The buying intention was also assessed, from "would certainly buy" to "certainly wouldn't buy" (5 levels). This analysis will give us the estimation of the general consumer perception and acceptation, of the newly developed pasta, against a pasta control without spirulina.

\subsection{Statistical analysis}

Statistical analysis of the experimental data was performed using RStudio (Version 1.1.463 - (C) 2009-2018 RStudio, Inc.), through variance analysis (one-way ANOVA), by the Tukey test - Post Hoc Comparison at a significance level of $95 \%(\mathrm{p}<0.05)$. All results are presented as mean \pm standard deviation (SD).

\section{Results and discussion}

Samples with at least $10 \%$ microalgal biomass incorporation resulted in pasta dough with high adhesiveness and poor manufacturing abilities, which did not allow pasta lamination. Pasta dough with 4 and $5 \%$ microalgae addition was still very difficult to manufacture and had a strong fishy odour. Besides, these formulations resulted in pasta with very high cooking loss. Due to both technological and sensorial limitations, most probably due to the high content in protein, responsible for the high adhesive character and solubility in cooking, the range of A. platensis incorporation was set between 1 and $3 \%$ for both biomasses (F\&M-C256 and Ox Nature) (Fig. 2).

\subsection{Cooking quality parameters}

The results obtained for the pasta cooking behaviour are presented in Fig. 3.

Cooking quality parameters are empirical determinations widely used to provide important indications about the pasta quality performance upon cooking. Pastas prepared with A. platensis present swelling power higher than the control. This can be explained by the capacity of the microalgae to absorb water and retain it within the starch-protein network. These results are confirmed by previous water absorption trials performed with the same A. platensis biomass [44], in which considerably higher water absorption (WA: $5.2 \mathrm{~g} / \mathrm{g}_{\text {alga }}$ ) was obtained in relation to rice flour (WA: $2.4 \mathrm{~g} / \mathrm{g}_{\text {flour }}$ ). Accordingly, water absorption was also affected ( $\mathrm{p}<0.05$ ) by the addition of microalgae biomass, which increased from $42.8 \%$ in the control pasta to $54.9-64.5 \%$ in microalgae pastas. These values were also similar to WR water absorption. In a wheat pasta, the gluten-protein network is responsible for maintaining the pasta physical integrity during cooking, leading to generally low cooking loss ( $\left.\mathrm{CL}_{\mathrm{WR}}: 1.45 \%\right)$. Although the GF pasta presented in this study has $64 \%$ less protein than WR, its structure, composed of Psyllium gel and rice flour, allows the reinforcement of the pasta matrix, with a significant $(\mathrm{p}<0.05)$ cooking loss decrease $(-56 \%)$, compared to WR. In a GF pasta, starch plays a decisive role as the main structuring agent, which is supported by the significant negative correlations $(\mathrm{p}<0.05)$ between carbohydrate content and all hydration properties of cooked pastas $\left(\mathrm{r}_{\mathrm{WA}}=-0.64, \mathrm{r}_{\text {swelling }}=-0.53\right.$; $\left.\mathrm{r}_{\mathrm{CL}}=-0.75\right)$.

In the GF pastas developed, rice flour was replaced with A. platensis, i.e. mainly carbohydrates were removed and protein $(+60 \%)$ and lipids $(+8 \%)$ were incorporated, thus rendering a pasta with significantly ( $\mathrm{p}<0.05$ ) more hydration capacity than the control. However, A. platensis biomasses addition negatively affected pasta cooking loss, as microalgae formulations presented values ranging from 2.08 to $3.44 \%$. This results from the weakness of the GF matrix, leading to an easily ruptured cooked pasta structure, and thus increasing the leached solids from pasta samples into the cooking water [45]. However, there is a tendency to cooking loss reduction with higher A. platensis incorporation level, probably due to the protein increment in the pasta matrix. It is worth mentioning that these cooking loss values are of the same magnitude of the ones reported in other works $[18,46,47]$ for semolina pastas enriched with this microalga, suggesting that the products obtained with Arthrospira platensis present high-quality in terms of cooking behaviour.

\subsection{Colour stability}

The results obtained for the pasta colour parameters, lightness $\left(\mathrm{L}^{*}\right)$, greenness (a*) and yellowness ( $\left.\mathrm{b}^{*}\right)$ can be seen in Table 2 .

The two A. platensis biomasses have slightly different impact on colour, especially in chromatic parameters $\left(\mathrm{a}^{*}\right.$ and $\left.\mathrm{b}^{*}\right)$ at $3 \%$ incorporation level, which is also evident from Fig. 2.

Regarding raw pasta samples, A. platensis pastas present significantly ( $\mathrm{p}<0.05$ ) lower lightness than control and WR pastas. Also, a reduction in all colour parameters, i.e. closer to the grey colour, with increasing algae concentration, can be observed. The results are similar for both A. platensis studied.

Regarding pasta colour stability upon cooking, all pasta samples showed significantly colour differences upon cooking $\left(\Delta \mathrm{E}^{*}=10.3-17\right)$, meaning that the differences between raw and cooked samples can be detected by regular human vision [48]. These results also indicate that a certain degree of leaching could occur, but this should mainly result from degradation of colour pigments [47]. This is supported by the greenish tonality of the cooking water, which indicates some degradation of chlorophylls and phycocyanin pigments. However, by increasing A. platensis incorporation level (of both biomasses), a lower $\Delta \mathrm{E}^{*}$ was observed which could indicate the resistance of the product to the thermal procedure applied [18]. Also, another observation is that

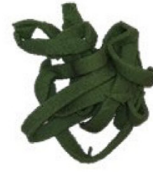

$1 \%$

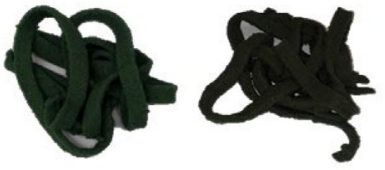

$3 \%$

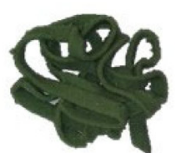

$1 \%$

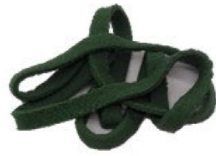

$2 \%$

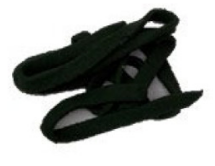

$3 \%$

Fig. 2. Pasta dough with A. platensis F\&MC256 (a) and Ox Nature (b) at 1\%,2\% and $3 \%$ incorporation level.

(a) 


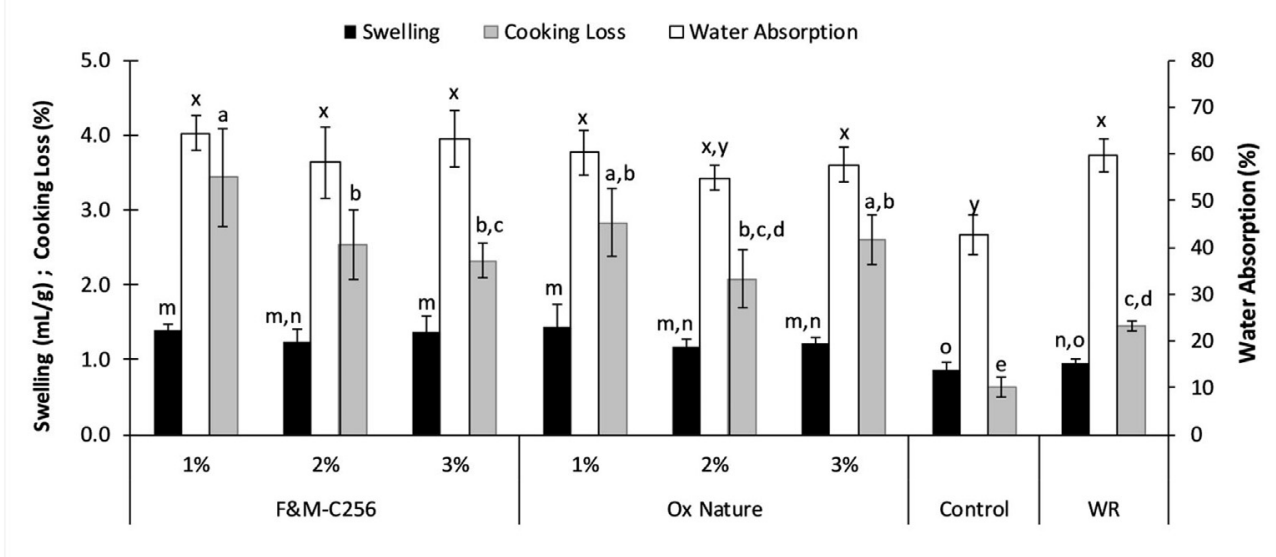

Fig. 3. Cooking quality parameters of GF pasta samples with $A$. platensis biomasses (F \&M-C256, Ox Nature), control (without $A$. platensis) and wheat reference (WR). Data shown is mean $\pm \mathrm{SD}, \mathrm{n}=3$. Different letters in the same parameter show significant differences ( $\mathrm{p}<0.05$, one-way ANOVA post-hoc Tukey test). chromatic parameters values, after cooking, are independent of $A$. platensis biomass concentration, suggesting that a minimum pigment leaching always occurs, probably due to a partial degradation of chlorophylls and phycocyanins. A similar phenomenon was observed in studies with gluten-free pasta enriched with legume flours [2].

Colourful eating is associated with healthy choices in food consumption [49]. Moreover, regarding thermally processed foods, such as pasta, consumers expect that a good quality pasta should maintain its colour, even after cooking [1].

To our knowledge there are no studies focusing on the supplementation of gluten-free pasta with A. platensis. The similarity of these results with those from wheat pasta is a clear indication of the good quality of the developed product.

\subsection{Mechanical properties of dough and pasta}

\subsubsection{Rheology characterization of pasta dough}

The results from the small amplitude dynamic rheological measurements (Fig. 4) of the uncooked pasta are expressed in terms of storage $\left(\mathrm{G}^{\prime}\right)$ and loss $\left(\mathrm{G}^{\prime \prime}\right)$ moduli.

For all dough samples $G^{\prime}$ was higher than $G^{\prime \prime}$, over the frequency range tested, and both moduli increased with increasing frequency. This behaviour translates into a weak gel-like network and is more noticeable in the wheat reference pasta (WR), as can be observed by the parameter $\mathbf{b}^{\prime}$ of the resulting power law (Table 3). When compared to the control dough, the addition of $1 \%$ microalga (and also $2 \%$ for Ox) causes the reinforcement of the dough structure ( $\alpha^{\prime}$ increases). Since both $A$. platensis biomasses present similar biochemical composition (Table 1), the difference between supplemented pastas is probably due to the different drying method applied in A. platensis processing, being the commercial product more favourable in terms of restructuring.
As A. platensis level of incorporation continues to increase, pasta dough becomes less elastic and less stable, revealed by an increase in $b^{\prime}$ values. As previously stated, the building of GF pasta structure is mainly achieved through gelatinization phenomena. So, only after cooking, i.e. after gelatinization, starch assumes the major role, resulting in a more extensible pasta compared with control (Table 4). In another study [19], the authors found that this microalga reinforced the structure of cookies in terms of texture properties.

GF doughs seem to be more structured, since viscoelastic moduli are less frequency dependent than in the case of WR. However, WR dough presents higher $\mathrm{G}^{\prime}$ and $\mathrm{G}^{\prime \prime}$ associated with higher structured material, as corroborated by extensibility results.

\subsubsection{Texture properties of cooked pasta}

After cooking, the pasta texture properties were evaluated by penetration (Fig. 5) and tension tests (Table 4). The main mechanical properties in terms of quality of the cooked pasta include high firmness, high elasticity, low stickiness and surface integrity [1,50].

Firmness values of developed cooked pastas were lower (1.60 to $2.10 \mathrm{~N}$ ), as expected, than the results reported earlier [18,46] for wheat pastas supplemented with $A$. platensis. Unlike in wheat pastas, firmness of GF pastas does not appear to be directly related with its protein content ( $\mathrm{p}<0.05$ ); although there were small differences, $<1 \mathrm{~N}$, the highest firmness values were observed in control pasta and in Ox_3\%, which presented the lowest $(3.88 \%)$ and highest protein $(8.89 \%)$ values, respectively. However, Larrosa et al. [51] found that both water and protein contents strongly affected GF pasta firmness, which is probably due to the differences between pasta matrix of both studies, especially protein types [52]. Moreover, control pasta presented $+28 \%$ firmness than WR (Fig. 5a), justifying the importance of carbohydrates in these products.

Table 2

Colour parameters $\left(\mathrm{L}^{*}, \mathrm{a}^{*}, \mathrm{~b}^{*}\right)$ of raw and cooked pasta samples with A. platensis biomass incorporation (F\&M-C256 and Ox Nature), control (without A. platensis), and wheat reference (WR).

\begin{tabular}{|c|c|c|c|c|c|c|c|}
\hline & & \multicolumn{3}{|l|}{ Raw pasta } & \multicolumn{3}{|l|}{ Cooked pasta } \\
\hline \multirow[t]{2}{*}{ F\&M-C256 } & $1 \%$ & $48.85 \pm 0.83^{\mathrm{c}}$ & $-14.24 \pm 0.21^{\mathrm{j}, \mathrm{k}}$ & $10.86 \pm 0.14^{\mathrm{g}, \mathrm{h}}$ & $41.03 \pm 5.47^{\mathrm{d}}$ & $-1.38 \pm 0.16^{\mathrm{c}, \mathrm{d}}$ & $18.81 \pm 2.69^{c}$ \\
\hline & $3 \%$ & $32.61 \pm 1.01^{\mathrm{f}}$ & $-8.95 \pm 0.40^{g}$ & $6.71 \pm 0.31^{\mathrm{i}}$ & $30.33 \pm 2.49^{f}$ & $-1.41 \pm 0.11^{\mathrm{c}, \mathrm{d}, \mathrm{e}}$ & $15.57 \pm 1.11^{\mathrm{d}}$ \\
\hline \multirow[t]{3}{*}{ Ox Nature } & $1 \%$ & $47.84 \pm 0.37^{\mathrm{c}}$ & $-14.37 \pm 0.08^{\mathrm{k}}$ & $11.55 \pm 0.08^{\mathrm{f}, \mathrm{g}}$ & $42.47 \pm 2.25^{\mathrm{d}}$ & $-1.81 \pm 0.16^{\mathrm{e}}$ & $18.63 \pm 1.33^{\mathrm{c}}$ \\
\hline & $2 \%$ & $38.17 \pm 0.70^{\mathrm{d}, \mathrm{e}}$ & $-13.35 \pm 0.28^{\mathrm{i}}$ & $10.14 \pm 0.30^{\mathrm{g}, \mathrm{h}}$ & $33.85 \pm 2.68^{\mathrm{e}, \mathrm{f}}$ & $-1.82 \pm 0.22^{\mathrm{e}}$ & $14.57 \pm 1.16^{\mathrm{d}, \mathrm{e}}$ \\
\hline & $3 \%$ & $31.90 \pm 1.34^{\mathrm{f}}$ & $-11.08 \pm 0.37^{\mathrm{h}}$ & $9.03 \pm 0.21^{\mathrm{h}}$ & $30.40 \pm 2.47^{\mathrm{f}}$ & $-1.80 \pm 0.34^{\mathrm{d}, \mathrm{e}}$ & $13.33 \pm 0.83^{\mathrm{e}, \mathrm{f}}$ \\
\hline
\end{tabular}

Results are expressed as mean $\pm \mathrm{SD}, \mathrm{n}=8$. Different letters in the same parameter (e.g., $\mathrm{L}^{*}$ raw and cooked) show significant differences ( $\mathrm{p}<0.05$, one-way ANOVA post-hoc Tukey test). 


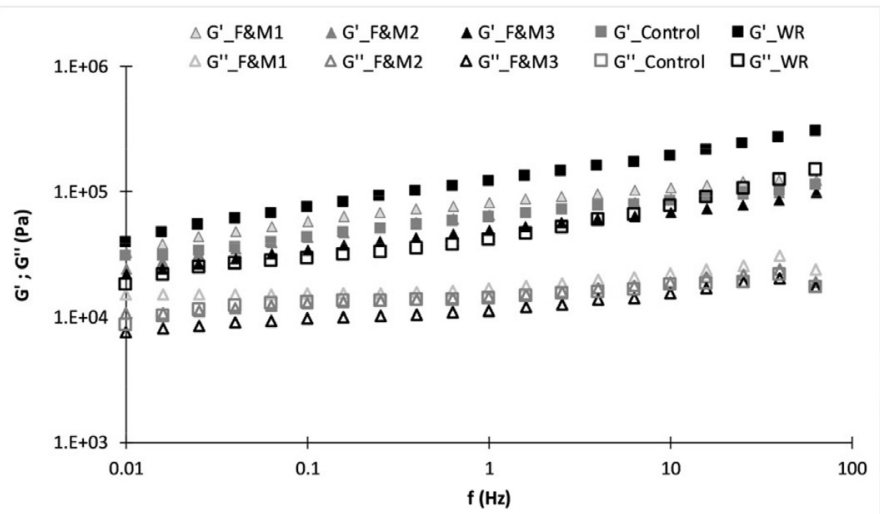

(a)

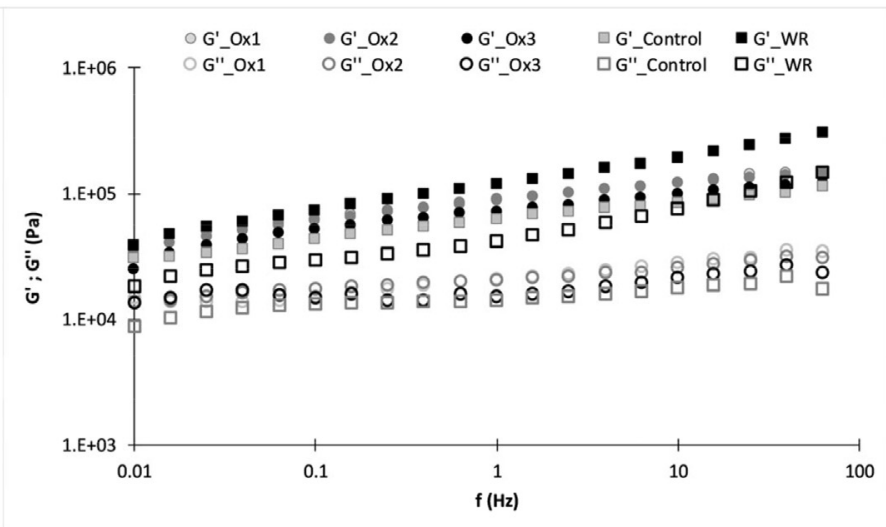

(b)

Fig. 4. Mechanical spectra of pasta dough with a) A. platensis F\&M-C256 (1, 2, 3\%), and b) A. platensis Ox (1, 2, 3\%), control (without A. platensis) and wheat reference (WR). Closed symbols-G'; open symbols-G".

Stickiness is perceived by consumers as a negative feature, being also undesirable for food packaging [36]. Stickiness values ranged from 1.76 to $2.54 \mathrm{~N}$, with WR showing the highest value. A. platensis biomass addition did not appear to influence this texture characteristic.

Increasing the protein content of durum spaghetti has been shown to decrease stickiness [53]. In our study, this reported relationship was not found ( $\mathrm{p}<0.05$ ), indicating once again that texture properties of GF pasta also depend on other factors than uniquely on protein content. Pasta surface stickiness is related to the amount of starch granules that exudate from the pasta matrix into the cooking water and coats the surface of the product, being a reliable indicator of cooked pasta quality [54]. Indeed, there is a positive significant correlation $(\mathrm{r}=0.582$, $\mathrm{p}<0.05$ ) between stickiness and cooking loss, in agreement with Larrosa et al. [51] studies on GF pastas with corn flour.

Adhesiveness values ranged between 0.02 and 0.09 -N.s and were similar to those reported by Martinez et al. [55] for commercial wheat pastas. As expected, a positive relationship between cooking loss and adhesiveness ( $\mathrm{r}=0.647, \mathrm{p}<0.05)$ was observed. A clear decrease $(\mathrm{p}<0.05)$ in adhesiveness with the increase of $A$. platensis incorporation level was observed, indicating that this microalga contributed to the reinforcement of the internal structure of cooked pasta. Rheology results appear not to corroborate these findings, but they refer to uncooked pasta dough, i.e. we are comparing two different materials. The reinforcement of the structure "is visible" only after starch gelatinisation in cooked pasta.

Extensibility is an important characteristic of pasta, and in wheatbased pasta results mostly from the presence of gluten proteins, with glutenin being highly associated with the resistance to extension (Rmax) [56]. As expected, WR shows significantly ( $<<0.05$ ) higher extensibility parameters (resistance and distance until rupture) when
Table 4

Extensibility parameters (Rmax - resistance to extension; ERmax - Distance until rupture) of cooked pasta samples with A. platensis incorporation (F\&MC256 and Ox Nature), control (without $A$. platensis) and wheat reference pasta (WR).

\begin{tabular}{llll}
\hline & & $R \operatorname{lmax}(\mathrm{N})$ & ERmax $(\mathrm{mm})$ \\
\hline F\&M-C256 & $1 \%$ & $0.51 \pm 0.13^{\mathrm{b}, \mathrm{c}}$ & $5.40 \pm 1.12^{\mathrm{z}}$ \\
& $2 \%$ & $0.40 \pm 0.12^{\mathrm{c}}$ & $5.21 \pm 1.42^{\mathrm{z}}$ \\
Ox Nature & $0.60 \pm 0.25^{\mathrm{b}}$ & $6.90 \pm 1.89^{\mathrm{y}, \mathrm{z}}$ \\
& $1 \%$ & $0.53 \pm 0.13^{\mathrm{b}, \mathrm{c}}$ & $6.19 \pm 1.27^{\mathrm{y}, \mathrm{z}}$ \\
Control & $0.65 \pm 0.12^{\mathrm{b}}$ & $7.22 \pm 1.57^{\mathrm{y}}$ \\
WR & $3 \%$ & $0.65 \pm 0.15^{\mathrm{b}}$ & $6.15 \pm 1.78^{\mathrm{y}, \mathrm{z}}$ \\
& & $0.64 \pm 0.10^{\mathrm{b}}$ & $6.15 \pm 0.74^{\mathrm{y}, \mathrm{z}}$ \\
\hline
\end{tabular}

Data shown is mean $\pm S D, n=3$. Different letters in the same parameter show significant differences ( $\mathrm{p}<0.05$, one-way ANOVA post-hoc Tukey test).

compared to the GF pasta developed (Table 4). There is no correlation between pasta protein content and the extensibility parameters, reinforcing the reduction on the importance of the protein content on GF pasta, unlike gluten proteins in wheat pasta, as referred earlier.

Results of the physical parameters of dough and cooked pasta, related with the quality of the products, revealed similar behaviour regardless of $A$. platensis biomass incorporation level and origin. However, from a biochemical point of view, and based on previous works with A. platensis [18,19,44,57], the incorporation level will have a considerable impact on the nutritional quality of the final product. Therefore, the studies were continued with the two highest $A$. platensis concentrations (2 and $3 \%$ ).

Table 3

Power law parameters $\left(\alpha^{\prime}, \alpha^{\prime \prime}, \mathrm{b}^{\prime}\right.$ and $\left.\mathrm{b}^{\prime \prime}\right)$ of uncooked pasta samples with A. platensis (F\&M-C256 and Ox Nature), control (without A. platensis), wheat reference (WR).

\begin{tabular}{|c|c|c|c|c|c|}
\hline & & \multicolumn{2}{|l|}{$\mathrm{G}^{\prime}$} & \multicolumn{2}{|l|}{$\mathrm{G}^{\prime \prime}$} \\
\hline \multirow[t]{2}{*}{ F\&M-C256 } & $1 \%$ & $80,978 \pm 5215$ & $0.14 \pm 0.01$ & $19,521 \pm 1472$ & $0.09 \pm 0.01$ \\
\hline & $3 \%$ & $49,281 \pm 5529$ & $0.16 \pm 0.01$ & $12,553 \pm 2315$ & $0.10 \pm 0.02$ \\
\hline \multirow[t]{3}{*}{ Ox Nature } & $1 \%$ & $91,714 \pm 12,396$ & $0.15 \pm 0.01$ & $23,007 \pm 2855$ & $0.12 \pm 0.03$ \\
\hline & $2 \%$ & $82,027 \pm 6989$ & $0.16 \pm 0.01$ & $20,807 \pm 1532$ & $0.09 \pm 0.01$ \\
\hline & $3 \%$ & $64,044 \pm 4981$ & $0.16 \pm 0.01$ & $15,734 \pm 1009$ & $0.11 \pm 0.04$ \\
\hline
\end{tabular}

The goodness of fitting (R2) ranged from 0.890 to 0.998 . Data shown is mean $\pm \mathrm{SD}, \mathrm{n}=3$. 


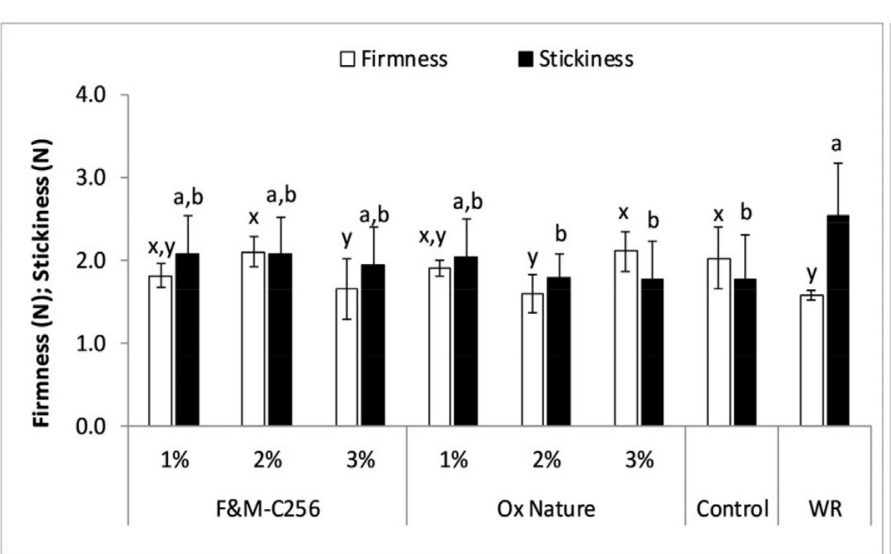

(a)

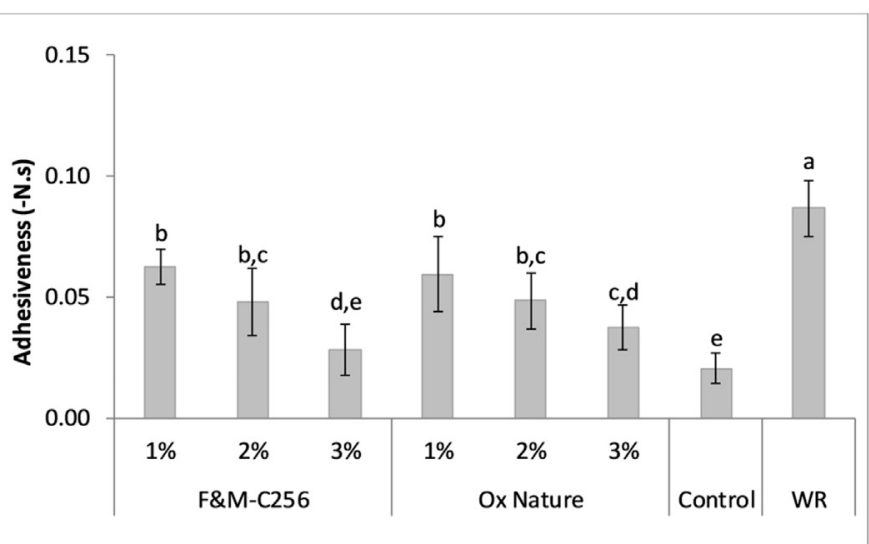

(b)

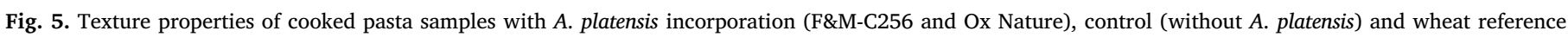

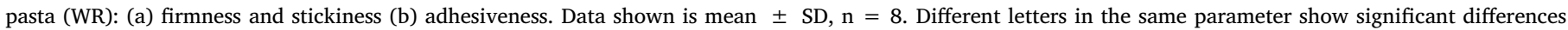
( $\mathrm{p}<0.05$, one-way ANOVA post-hoc Tukey test).

\subsection{Proximate chemical composition}

Table 5 presents the proximate chemical composition of the selected cooked pasta samples.

For consumers, the main issue of GF foods is their high energy value, arising mainly from high lipid content. From proximate composition results, similar energy values (344.4-399.7 kcal/100 g, d.b.) were observed in all cooked pasta. All pasta samples presented high moisture values (59.45 to $68.46 \%$ ) consistent with the results from water absorption (Fig. 3). As expected, pastas incorporated with $A$. platensis biomasses showed a significantly lower $(\mathrm{p}<0.05)$ carbohydrate content and higher ash levels compared to control. Carbohydrates are the major component of cooked pastas, representing $93.19 \%(\mathrm{w} / \mathrm{w})$ of control pasta, which is mainly composed of rice flour. With the incorporation of microalgae biomasses, rice flour is replaced by A. platensis biomass; consequently, the carbohydrate content of microalgae enriched pastas decreases in relation to the control sample. The incorporation of $A$. platensis biomass resulted in considerable improvements of the protein content in the final product, which results from the high concentration of these macromolecules in microalgae biomass (Table 1 ). Knowing the contribution of $A$. platensis biomass addition on pasta properties is fundamental to extend the utilization of this cyanobacterium and consequently successful novel foods development. Therefore, from the nutritional point of view, this is a more complex food, more interesting for diets aiming at weight control.

The presence of heavy metals in microalgae is a growing issue. As seen in Table 1, both A. platensis biomasses show differentiated levels of heavy metals, with $A$. platensis Ox Nature showing higher values, especially from arsenic (As) and lead ( $\mathrm{Pb}$ ). More attention should be paid to A. platensis cultivation conditions, due to the biosorption capacity of this cyanobacterium, in order to prevent possible heavy metals contamination. The concentration limits in plant foods according to Reg. (EC) 629/2008 [58] for lead and cadmium varied from 0.005 and $0.2 \mathrm{mg} / \mathrm{kg}$ of fresh weight and from 0.5 and $0.2 \mathrm{mg} / \mathrm{kg}$ of fresh weight, respectively. The Joint FAO/WHO Committee on Food Additives also analysed, for each heavy metal, the presumable tolerable weekly dose (PTWI), that represents the quantity of heavy metal (expressed in $\mu \mathrm{g} / \mathrm{kg}$ of body weight in a week) that an adult man can absorb without health damages. Assuming the optimal average pasta intake is equal to $1.06 \mathrm{~g} /$ $\mathrm{kg}$ of body weight per day [59], the estimated PTWI for the four metals detected in pastas integrated with $3 \%$ A. platensis biomasses respects the limits gave by FAO/WHO for arsenic, cadmium, lead, and mercury (15, 7, 25 and $5 \mu \mathrm{g} / \mathrm{kg}$ body weight).

\subsection{Bioactive compounds and antioxidant capacity}

In the case of $A$. platensis pasta samples, higher amounts of TPC were found at 3\% A. platensis incorporation level (Fig. 6a).

Pastas with A. platensis F\&M-C256 or Ox Nature biomasses present significant $(\mathrm{p}<0.05)$ differences in TPC contents. Since both A. platensis biomasses present similar biochemical composition, the different TPC contents could be due to their drying methods: A. platensis F\&MC256 biomass was lyophilized while $A$. platensis Ox Nature biomass was dried by spray-drying, a method that causes cell wall disruption and thus the release of significantly higher phenolic compounds than lyophilisation, as reported by Nouri and Abbasi [60]. In a previous study with A. platensis F\&M-C256 biomass supplemented cookies, the authors reported $0.43 \mathrm{mg} \mathrm{GAE} / \mathrm{g}$ [19], which is higher than the value obtained in the present study for GF pasta $(0.24 \mathrm{mg} \mathrm{GAE} / \mathrm{g})$ for the same $A$. platensis biomass and incorporation level (2\%). Although the matrices analysed were very different and this could have led to differences in the measured TPC values, part of this difference may also be explained

Table 5

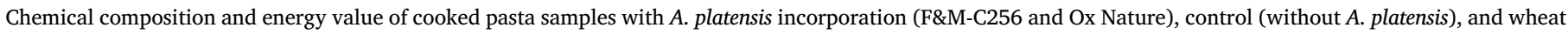
reference (WR).

\begin{tabular}{|c|c|c|c|c|c|c|c|}
\hline \multicolumn{2}{|l|}{ Sample } & \multirow{2}{*}{$\frac{\text { Protein }}{\text { (\% w/w, dry basis })}$} & \multirow[t]{2}{*}{ Lipids } & \multirow[t]{2}{*}{ Ash } & \multirow[t]{2}{*}{ Carbohydrates } & \multirow{2}{*}{$\begin{array}{l}\text { Moisture } \\
(\% \mathrm{w} / \mathrm{w})\end{array}$} & \multirow{2}{*}{$\begin{array}{c}\text { Energy value } \\
\text { (kcal/100 g) }\end{array}$} \\
\hline & & & & & & & \\
\hline \multirow[t]{2}{*}{ F\&M-C256 } & $2 \%$ & $4.0 \pm 0.5^{c}$ & $1.2 \pm 0.00^{\mathrm{d}}$ & $0.9 \pm 0.1^{\mathrm{b}}$ & $79.3 \pm 1.5^{\mathrm{b}}$ & $68.2 \pm 2.8^{\mathrm{a}}$ & 344.4 \\
\hline & $3 \%$ & $5.2 \pm 1.3^{\mathrm{b}, \mathrm{c}}$ & $2.2 \pm 0.2^{\mathrm{a}}$ & $1.2 \pm 0.2^{\mathrm{b}}$ & $82.3 \pm 3.0^{\mathrm{b}}$ & $68.5 \pm 0.9^{\mathrm{a}}$ & 369.8 \\
\hline \multirow[t]{2}{*}{ Ox Nature } & $2 \%$ & $6.5 \pm 0.5^{\mathrm{b}}$ & $1.5 \pm 0.1^{\mathrm{c}}$ & $0.8 \pm 0.1^{\mathrm{b}}$ & $80.1 \pm 5.5^{\mathrm{b}}$ & $66.0 \pm 1.9^{\mathrm{a}}$ & 359.8 \\
\hline & $3 \%$ & $8.9 \pm 0.7^{\mathrm{a}}$ & $1.9 \pm 0.1^{\mathrm{b}}$ & $1.1 \pm 0.1^{\mathrm{b}}$ & $80.2 \pm 0.3^{\mathrm{b}}$ & $67.7 \pm 1.4^{\mathrm{a}}$ & 373.5 \\
\hline Control & & $3.9 \pm 1.0^{\mathrm{c}}$ & $1.3 \pm 0.1^{\mathrm{c}, \mathrm{d}}$ & $0.4 \pm 0.4^{\mathrm{a}}$ & $93.2 \pm 4.1^{\mathrm{a}}$ & $61.3 \pm 2.6^{\mathrm{b}}$ & 399.7 \\
\hline WR & & $6.0 \pm 1.2^{\mathrm{b}}$ & $1.4 \pm 0.1^{\mathrm{c}, \mathrm{d}}$ & $0.8 \pm 0.1^{\mathrm{b}}$ & $83.1 \pm 2.7^{\mathrm{b}}$ & $59.5 \pm 1.0^{\mathrm{b}}$ & 369.3 \\
\hline
\end{tabular}

Data shown is mean $\pm \mathrm{SD}, \mathrm{n}=3$. Different letters in the same parameter show significant differences (p $<0.05$, one-way ANOVA post-hoc Tukey test). 


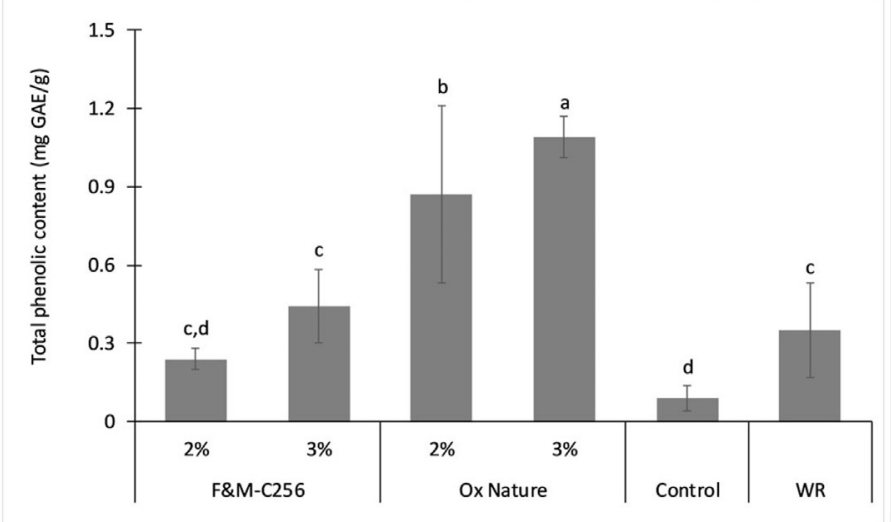

(a)

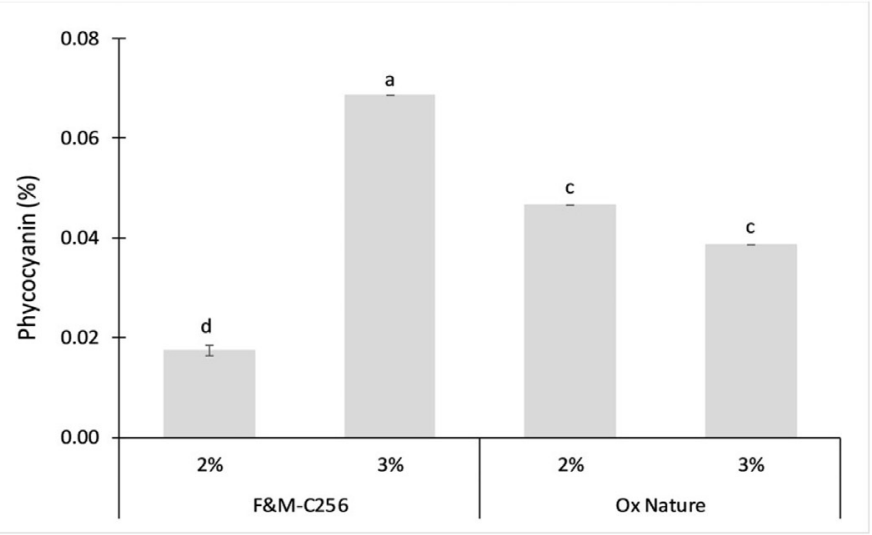

(b)

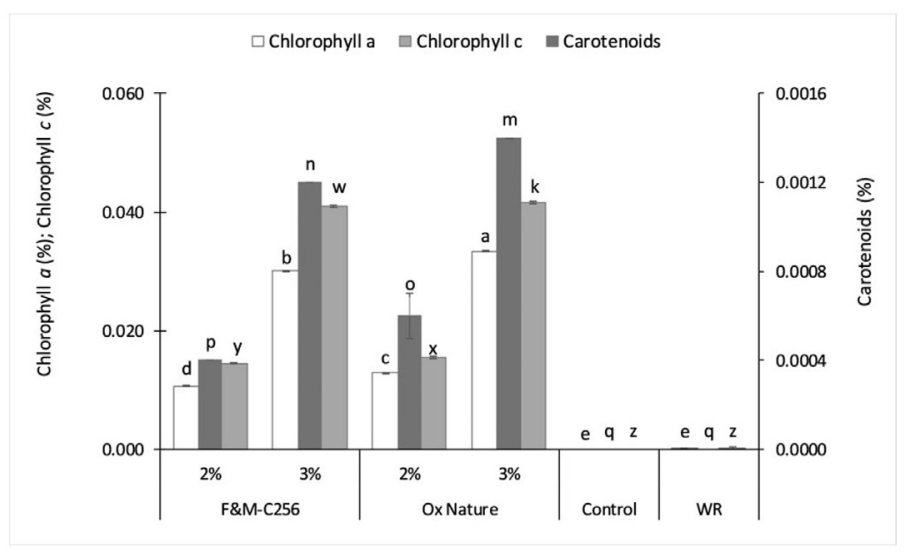

(c)

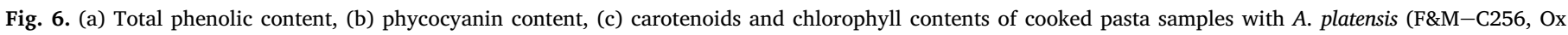

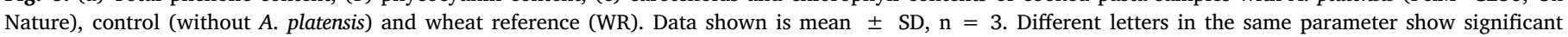
differences ( $\mathrm{p}<0.05$, one-way ANOVA post-hoc Tukey test).

by the fact that TPC are hydrophilic molecules, so during pasta processing they could be leached into the cooking water.

A. platensis is also known for the presence of phycocyanin a natural blue pigment used as food colorant. It is reported that phycocyanin acts as antioxidant against free radicals, and was found to be 16 times more efficient as an antioxidant than trolox and about 20 times more efficient than ascorbic acid against haemolysis induced by peroxyl radicals in human erythrocytes [61,62].

Phycocyanin content varied between 17 and $69 \mathrm{mg} / 100 \mathrm{~g}$ of cooked pasta (d.b), with pasta integrated with $3 \%$ A. platensis F\&M-C256 biomass presenting the highest value (Fig. $6 \mathrm{~b}$ ). The differences in phycocyanin content observed between pastas integrated with $A$. platensis $\mathrm{F} \&$ M-C256 and A. platensis from Ox Nature could be due to different culture conditions, growth phase and physiological status adopted for the two microalgae that can influence the content of the biochemical components in algal cells [22]. A lower amount of phycocyanin when $3 \%$ A. platensis from Ox Nature was added in pasta compared to the $2 \%$ formulation was also observed. Considering that phycocyanin shows a high sensitivity to heat [63], it is probable that even following the same production process for pastas added with 2 and $3 \%$ A. platensis from Ox Nature, the manipulations adopted for pasta development and the drying procedure influenced its degradation. The two A. platensis biomasses presented significantly $(\mathrm{p}<0.05)$ different amounts of these pigments, probably due to different culture conditions and drying methods.

Alves-Rodrigues and Shao [64] found carotenoids in Chlorella are not only an important natural food colorant and additive but also an effective stimulant of the immune response, hampering cataract and atherosclerotic development and they may reduce the risk of cardiovascular diseases and delay chronic disease. Also, microalgae chlorophylls are used as natural colorant in food and they are also known as antitumor and anti-inflammatory agent [65]. The addition of A. platensis biomass resulted in an effective supplementation of carotenoids and chlorophylls, which are absent in the control and WR pastas (Fig. 6c).

Gluten-free pastas present significantly $(\mathrm{p}<0.05)$ higher scavenging activity than wheat pasta. A. platensis pastas show increasing antioxidant activity (DPPH and VCEAC) with increasing biomass concentration and no significant $(\mathrm{p}<0.05)$ differences between the two biomasses was observed (Table 6).

The improvement in the presence of bioactive compounds observed in supplemented pastas led to a substantial improvement of the antioxidant activity of these pastas, as reported extensively [61]. In spite of pasta processing and cooking, A. platensis biomass enhanced the nutritional properties by increasing the antioxidant activity of the GF pasta as already reported by Zouari et al. [46] for A. platensis enriched semolina pasta. Moreover, phenolics of $A$. platensis biomass can increase both bioactivity and nutritional potential as El Gharras [66] stated for 
Table 6

Antioxidant capacity of cooked pasta samples with A. platensis biomass (F\& M-C256, Ox Nature), control (without A. platensis) and wheat reference (WR).

\begin{tabular}{llll}
\hline Sample & & DPPH radical scavenging capacity $(\%)$ & VCEAC $(\mu \mathrm{g} / \mathrm{g})$ \\
\hline F\&M-C256 & $2 \%$ & $56.88 \pm 2.06^{\mathrm{b}}$ & $0.56 \pm 0.04^{\mathrm{c}}$ \\
& $3 \%$ & $67.97 \pm 1.30^{\mathrm{a}}$ & $0.71 \pm 0.02^{\mathrm{b}}$ \\
Ox Nature & $2 \%$ & $56.02 \pm 1.70^{\mathrm{b}}$ & $0.55 \pm 0.02^{\mathrm{c}}$ \\
& $3 \%$ & $70.33 \pm 4.36^{\mathrm{a}}$ & $0.77 \pm 0.02^{\mathrm{a}}$ \\
Control & & $50.93 \pm 2.01^{\mathrm{c}}$ & $0.52 \pm 0.02^{\mathrm{d}}$ \\
WR & & $46.62 \pm 3.19^{\mathrm{d}}$ & $0.44 \pm 0.03^{\mathrm{e}}$
\end{tabular}

Data shown is mean $\pm \mathrm{SD}, \mathrm{n}=3$. Different letters in the same parameter show significant differences ( $\mathrm{p}<0.05$, one-way ANOVA post-hoc Tukey test).

fruits, what also applies for microalgae.

\subsection{In vitro digestibility}

In the last years several studies have been conducted on the in vitro digestibility (IVD) of several food matrices, in order to determine the structural and chemical changes that occur in different foods under simulated gastrointestinal conditions [67]. Regarding IVD of microalgae-based foods, a previous study [19] indicated that IVD of microalgae cookies showed no significant $(\mathrm{p}<0.05)$ differences from the control. To our knowledge, there are no studies regarding IVD in glutenfree foods supplemented with microalgae. In the present study, differences were found in dry matter IVD (Table 7). Considering the IVD of $A$. platensis F\&M-C256 biomass is around $80 \%$ [19], as expected, to a higher amount of microalgal biomass correspond a decrease in digestibility. The differences between pastas with A. platensis F\&M-C256 and A. platensis from Ox Nature can be related to the different biochemical composition of the two microalgal biomasses due to different culture conditions adopted during cultivation [22] that could have influenced pasta IVD. Carbohydrate digestibility was also similar for all pasta samples (Table 7), while differences emerged in protein digestibility. The control pasta is composed of Psyllium husk, which presents large amounts of soluble fibre (Table 1), resulting in a low protein IVD of control pasta compared to WR. Other authors reported low protein digestibility of GF pasta with hydrocolloids (19.7\%) due to the network formed by them, which encapsulates the starch and avoids enzyme action [68].

In this study, protein IVD showed different trends for pastas with the two A. platensis biomasses. Pastas supplemented with A. platensis biomass from Ox Nature presented an increase in IVD, while pasta with $A$. platensis F\&M-C256 biomass at 3\% incorporation level slightly reduced the protein digestibility. In a study on wheat pasta with $5 \%$ A. platensis biomass, the authors found a higher protein IVD (71.04\%) [57] compared to the protein IVD found in our study for pastas incorporated with $3 \%$ A. platensis biomasses. This study refers to wheat-based products, which leads to very high digestibility values when compared to those from the present study, which is supported by the higher protein IVD

Table 7

In vitro digestibility of cooked pasta samples with $A$. platensis biomass (F\& $\mathrm{M}-\mathrm{C} 256$, Ox Nature), control (without A. platensis) and wheat reference (WR).

\begin{tabular}{|c|c|c|c|c|}
\hline \multirow[t]{2}{*}{ Sample } & & \multicolumn{3}{|c|}{ In vitro digestibility (\%) } \\
\hline & & Dry matter & Protein & Carbohydrate \\
\hline \multirow[t]{2}{*}{ F\&M-C256 } & $2 \%$ & $92.09 \pm 1.03^{\mathrm{a}, \mathrm{b}, \mathrm{c}}$ & $27.97 \pm 6.00^{\mathrm{b}}$ & $93.51 \pm 0.60^{\mathrm{a}, \mathrm{b}}$ \\
\hline & $3 \%$ & $90.84 \pm 0.33^{\mathrm{b}, \mathrm{c}}$ & $24.85 \pm 0.66^{b}$ & $93.08 \pm 0.07^{\mathrm{a}, \mathrm{b}}$ \\
\hline \multirow[t]{2}{*}{ Ox Nature } & $2 \%$ & $90.70 \pm 1.69^{\mathrm{b}, \mathrm{c}}$ & $44.98 \pm 1.00^{\mathrm{a}, \mathrm{b}}$ & $93.62 \pm 0.50^{\mathrm{a}, \mathrm{b}}$ \\
\hline & $3 \%$ & $89.67 \pm 0.70^{c}$ & $55.81 \pm 3.47^{\mathrm{a}, \mathrm{b}}$ & $92.84 \pm 0.31^{\mathrm{b}}$ \\
\hline Control & & $92.95 \pm 1.19^{\mathrm{a}, \mathrm{b}}$ & $36.33 \pm 3.07^{b}$ & $93.99 \pm 0.26^{\mathrm{a}}$ \\
\hline WR & & $94.52 \pm 2.10^{\mathrm{a}}$ & $62.61 \pm 8.98^{\mathrm{a}}$ & $93.84 \pm 0.51^{\mathrm{a}, \mathrm{b}}$ \\
\hline
\end{tabular}

Data shown is mean $\pm S D, n=3$. Different letters in the same parameter show significant differences ( $\mathrm{p}<0.05$, one-way ANOVA post-hoc Tukey test).

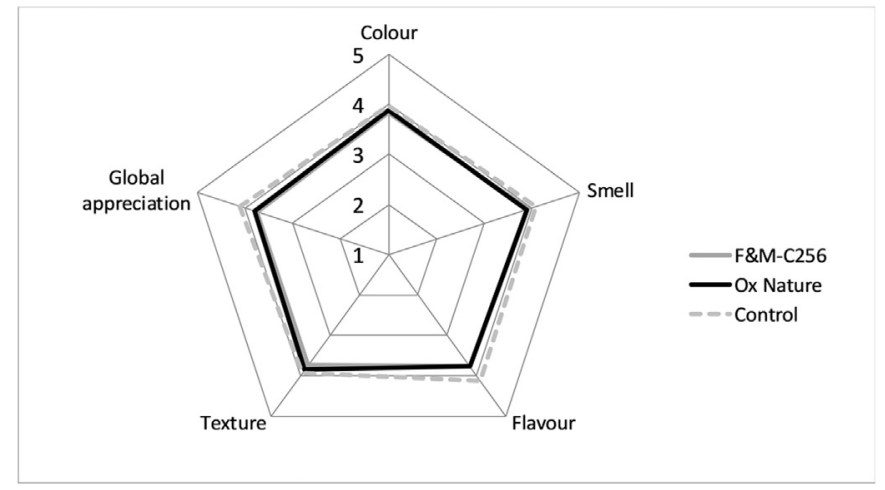

Fig. 7. Responses of the sensory analysis panel consumers $(n=31)$ regarding gluten-free pasta with $2 \%$ A. platensis F\&M-C256, Ox Nature and Control. 1 very unpleasant; 2 - unpleasant; 3 - slightly pleasant; 4 - pleasant; 5 - very pleasant.

value obtained for WR (62.61\%). Moreover, in vitro protein digestibility depends on the contents of phenolic compounds, polysaccharides and dietary fibre [69].

\subsection{Sensory evaluation}

Sensory analysis was performed with cooked pasta with both biomasses (A. platensis F\&M-C256 and Ox Nature) at $2 \%$ incorporation level, and control pasta. The selection of the optimum A. platensis concentration to perform this analysis was based on the bioactive and digestibility results from this work but also for comparison purposes with the results of other studies [18,46] with wheat pastas supplemented with $2 \%$ of $A$. platensis.

To our knowledge, there are no studies reporting sensory analysis of GF pasta with microalgae. From the literature reviewed concerning microalgae addition in wheat pasta, the formulations with $A$. platensis biomass seem to be the most appreciated by consumers [18].

From the average scores (Fig. 7) of the sensory parameters evaluated it is observed, although with a slight difference, that the consumer panel preferred the control sample, mainly due to the flavour component. Pastas produced with both A. platensis biomasses scored similarly in terms of flavour, smell and global appreciation, probably due (but not exclusively) to the similar biochemical composition of the pasta (Table 5). Earlier works $[18,46]$ obtained similar results for wheat pasta supplement with A. platensis biomass, at the same level of incorporation.

Regarding texture evaluation of pastas, the consumers scored all pastas similarly (3.7-3.9), which is in agreement with the results obtained from instrumental texture. About buying intention (Fig. 8), around $68 \%$ of consumers are more prone to acquire the control pasta.

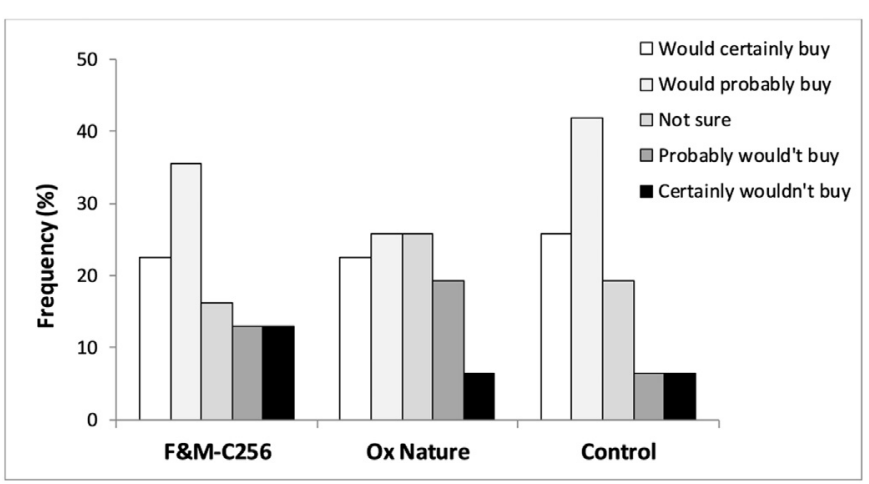

Fig. 8. Responses of the sensory analysis panel consumers regarding buying intention $(\mathrm{n}=31)$ of gluten-free pasta with $2 \%$ A. platensis F\&M-C256, Ox Nature and Control (without A. platensis). 
Between the supplemented pastas, the formulation that includes $A$. platensis F\&M-C256 biomass was the preferred, since around 58\% of consumers reported that they would buy or probably buy.

\section{Conclusions}

This study concludes that the use of microalgae biomass, namely Arthrospira platensis, resulted in a product with an attractive and innovative appearance and can considerable enhance the nutritional quality of pasta, without affecting its cooking and texture quality properties, with a favourable sensory evaluation.

The differences observed in the biochemical composition of the two A. platensis biomasses, due to different strain specific properties and different culture conditions and processing methods, led to pastas with differentiated bioactive contents and antioxidant capacity. This feature could lead to customized applications. For both A. platensis biomass increasing microalgae content resulted in a significant increase in the pasta antioxidant capacity. This study suggests that spirulina-based pastas could become widely consumed GF functional foods in the future.

\section{Declaration of competing interest}

A. platensis F\&M-C256 belongs to the Microalgae Culture Collection of Fotosintetica \& Microbiologica S.r.l., in which M.R. Tredici and L. Rodolfi have a financial interest; all the other authors have no conflicts of interest.

\section{Acknowledgments}

This work was supported by Portuguese funds from Fundação para a Ciência e a Tecnologia (Portugal) through the research unit UID/AGR/ 04129/2013 (LEAF). The authors wish to thank Società Agricola Serenissima S.S. (Italy) for providing the A. platensis F\&M-C256 biomass used in this work. P. F. acknowledges her PhD grant (C0144M) from University of Lisbon.

\section{Statement of informed consent, human/animal rights}

No conflicts, informed consent, human or animal rights applicable.

\section{References}

[1] M.A. Pagani, M. Lucisano, M. Mariotti, Traditional Italian products from wheat and other starchy flours, in: Y.H. Hui (Ed.), Handbook of Food Products Manufacturing, John Wiley \& Sons Inc, New Jersey, 2007, pp. 327-388.

[2] A. Bouasla, A. Wójtowicz, M.N. Zidoune, Gluten-free precooked rice pasta enriched with legumes flours: physical properties, texture, sensory attributes and microstructure, LWT Food Sci. Technol. 75 (2017) 569-577 https://doi.org/10.1016/j. lwt.2016.10.005.

[3] M. Fradique, A.P. Batista, M.C. Nunes, L. Gouveia, N.M. Bandarra, A. Raymundo, Isochrysis galbana and Diacronema vlkianum biomass incorporation in pasta products as PUFA's source, LWT Food Sci. Technol. 50 (2013) 312-319 https://doi.org/10. 1016/j.lwt.2012.05.006.

[4] D.I. Hedin, Gluten-free Globally - Important Considerations and Strategic Choices, Free From Food Expo, Euromonitor International, 2016, http://

finnishfoodinnovations.fi/wp-content/uploads/2017/05/Free-from-Marketprospects_INTRO_230517_Hedin_Euromonitor.pdf , Accessed date: 4 December 2019.

[5] NSF, How much do you know about gluten? NSF International Survey, http://www. nsf.org/newsroom/nsf-survey-finds-us-consumers-struggle-to-define-identifygluten, (2015) , Accessed date: 4 December 2019.

[6] T. Thompson, M. Dennis, L.A. Higgins, A.R. Lee, M.K. Sharrett, Gluten-free diet survey: are Americans with celiac disease consuming recommended amounts of fibre, iron, calcium and grain foods? J. Hum. Nutr. Diet. 18 (2005) 163-169 https://doi.org/10.1111/j.1365-277X.2005.00607.x.

[7] A.B. Nascimento, G.M.R. Fiates, A. dos Anjos, E. Teixeira, Gluten-free is not enough - perception and suggestions of celiac consumers, Int. J. Food Sci. Nutr. 65 (4) (2014) 394-398, https://doi.org/10.3109/09637486.2013.879286.

[8] FDA, CFR - code of federal regulations title 21, U.S. Food and Drug Administration, http://www.accessdata.fda.gov/scripts/cdrh/cfdocs/cfcfr/CFRSearch.cfm?fr = 101.81, (2012) , Accessed date: 3 May 2019.
[9] C. Cappa, M. Lucisano, M. Mariotti, Influence of Psyllium, sugar beet fibre and water on gluten-free dough properties and bread quality, Carbohydr. Polym. 98 (2013) 1657-1666 https://doi.org/10.1016/j.carbpol.2013.08.007.

[10] P. Fradinho, M.C. Nunes, A. Raymundo, Biscuits enriched with Psyllium fibre sensory evaluation and physicochemical comparison with market products, J. Food Sci. Technol. 52 (8) (2015) 4830-4840, https://doi.org/10.1007/s13197-0141549-6.

[11] F.J. Barba, Microalgae and seaweeds for food applications: challenges and perspectives, Food Res. Int. 99 (2017) 969-970 https://doi.org/10.1016/j.foodres. 2016.12.022.

[12] M.P. de Souza, M. Hoeltz, P.D. Gressler, L.B. Benitez, R.C.S. Schneider, Potential of microalgal bioproducts: general perspectives and main challenges, Waste Biomass Valoriz. (2018) 1-18, https://doi.org/10.1007/s12649-018-0253-6.

[13] F.J. Marti-Quijal, S. Zamuz, I. Tomašević, B. Gómez, G. Rocchetti, L. Lucini, F. Remize, F.J. Barba, J.M. Lorenzo, Influence of different sources of vegetable, whey and microalgae proteins on the physicochemical properties and amino acid profile of fresh pork sausages, LWT Food Sci. Technol. 110 (2019) 316-323 https:// doi.org/10.1016/j.lwt.2019.04.097.

[14] Regulation (EU) 2015/2283 of the European Parliament and of the Council of 25 November 2015 on novel foods, Official Journal of the European Communities, https://eur-lex.europa.eu/legal-content/EN/TXT/PDF/?uri = CELEX:32015R2283\& qid $=1551104546958 \&$ from $=$ PT, Accessed date: 3 May 2019.

[15] H.H. Abd El-Baky, F.K. El Baz, G.S. El-Baroty, Production of phenolic compounds from Spirulina maxima microalgae and its protective effects, Afr. J. Biotechnol. 8 (24) (2009) 7059-7067 https://academicjournals.org/journal/AJB/article-fulltext-pdf/D4B09D531593.

[16] L. Machu, L. Misurcova, J.V. Ambrozova, J. Orsavova, J. Mlcek, J. Sochor, T. Jurikova, Phenolic content and antioxidant capacity in algal food products, Molecules 20 (2015) 1118-1133, https://doi.org/10.3390/molecules20011118.

[17] A. Hongsthong, B. Bunnag, Biochemistry, biotechnology and applications, in: P.M. Gault, H.J. Marler (Eds.), Handbook on Cyanobacteria, Nova Science Publishers, New York, 2009, pp. 51-103.

[18] M. Fradique, A.P. Batista, M.C. Nunes, L. Gouveia, N.M. Bandarra, A. Raymundo, Chlorella vulgaris and Spirulina maxima biomass incorporation in pasta products, J. Sci. Food Agric. 90 (2010) 1656-1664, https://doi.org/10.1002/jsfa.3999.

[19] A.P. Batista, A. Niccolai, P. Fradinho, S. Fragoso, I. Bursic, L. Rodolfi, N. Biondi, M.R. Tredici, I. Sousa, A. Raymundo, Microalgae biomass as an alternative ingredient in cookies: sensory, physical and chemical properties, antioxidant activity and in vitro digestibility, Algal Res. 26 (2017) 161-171 https://doi.org/10.1016/j. algal.2017.07.017.

[20] A.P. Batista, L. Gouveia, N.M. Bandarra, J.M. Franco, A. Raymundo, Comparison of microalgal biomass profiles as novel functional ingredient for food products, Algal Res. 2 (2) (2013) 164-173 https://doi.org/10.1016/j.algal.2013.01.004.

[21] G. Chini Zittelli, V. Tomasello, E. Pinzani, M.R. Tredici, Outdoor cultivation of Arthrospira platensis during autumn and winter in temperate climates, J. Appl. Phycol. 8 (1996) 293-301 https://link.springer.com/content/pdf/10.1007\% 2FBF02178572.pdf.

[22] Q. Hu, Environmental effects on cell composition, in: A. Richmond, Q. Hu (Eds.), Handbook of Microalgal Culture: Biotechnology and Applied Phycology, Wiley, Oxford, 2004, pp. 83-93.

[23] Â. Matos, R. Feller, E.H.S. Moecke, J.V. de Oliveira, A.F. Junior, R.B. Derner, E.S. Sant'Anna, Chemical characterization of six microalgae with potential utility for food application, J. Am. Oil Chem. Soc. 93 (2016) 963-972.

[24] A.P. Batista, M.C. Nunes, P. Fradinho, L. Gouveia, I. Sousa, A. Raymundo, J.M. Franco, Novel foods with microalgal ingredients - effect of gel setting conditions on the linear viscoelasticity of Spirulina and Haematococcus gels, J. Food Eng. 110 (2012) 182-189 https://doi.org/10.1016/j.jfoodeng.2011.05.044.

[25] A.P. Batista, A. Niccolai, I. Bursic, L. Rodolfi, N. Biondi, M.R. Tredici, I. Sousa, A. Raymundo, Microalgae biomass incorporation in salted cookies ("crackers") in creases their functional properties, 4th EABA and EC Contractors' Conference and the 11th International Algae Congress, Berlin, Germany, 2017, p. 159.

[26] J. van Durme, K. Goiris, A. de Winne, L. de Cooman, K. Muylaert, Evaluation of the volatile composition and sensory properties of five species of microalgae, J. Agric. Food Chem. 61 (46) (2013) 10881-10890 https://doi.org/10.1021/jf403112k.

[27] X. Zeng, M.K. Danquah, S. Zhang, X. Zhang, M. Wu, X.D. Chen, I.-S. Nga, K. Jinga, Y. Lu, Autotrophic cultivation of Spirulina platensis for $\mathrm{CO}_{2}$ fixation and phycocyanin production, Chem. Eng. J. 183 (2012) 192-197, https://doi.org/10.1016/j. cej.2011.12.062.

[28] R. Dineshkumar, R. Narendran, P. Jayasingam, P. Sampathkumar, Cultivation and chemical composition of microalgae Chlorella vulgaris and its antibacterial activity against human pathogens, J. Aq. Mar. Biol. 5 (3) (2017) 00119, , https://doi.org/ 10.15406/jamb.2017.05.00119.

[29] G. Chini Zittelli, N. Biondi, L. Rodolfi, M.R. Tredici, Photobioreactors for mass production of microalgae, in: A. Richmond, Q. Hu (Eds.), Handbook of Microalgal Culture: Biotechnology and Applied Phycology, Wiley, Oxford, 2013, pp. 225-266, https://doi.org/10.1002/9781118567166.ch13.

[30] M.R. Tredici, N. Bassi, M. Prussi, N. Biondi, L. Rodolfi, G. Chini Zittelli, G. Sampietro, Energy balance of algal biomass production in a 1-ha "Green Wall Panel" plant: how to produce algal biomass in a closed reactor achieving a high net energy ratio, Appl. Energy 154 (2015) 1103-1111 https://doi.org/10.1016/j. apenergy.2015.01.086.

[31] M.R. Tredici, L. Rodolfi, N. Biondi, N. Bassi, G. Sampietro, Techno-economic analysis of microalgal biomass production in a 1-ha Green Wall Panel (GWP ${ }^{\circledR}$ ) plant, Algal Res. 19 (2016) 253-263 https://doi.org/10.1016/j.algal.2016.09.005.

[32] C. Zarrouk, Contribution à l'étude d'une cyanophycée. Influence de divers facteurs physiques et chimiques sur la croissance et la photosynthèse de Spirulina maxima 
(Setch et Gardner) Geitler, PhD Thesis Université de Paris, France, 1966.

[33] P. Fradinho, I. Sousa, A. Raymundo, Functional and thermorheological properties of rice flour gels for gluten-free pasta applications, Int. J. Food Sci. Technol. 54 (4) (2019) 1109-1120 https://doi.org/10.1111/ijfs.14001.

[34] A. Paraskevopoulou, V. Kiosseoglou, S. Alevisopoulos, S. Kasapis, Small deformation properties of model salad dressings prepared with reduced cholesterol egg yolk, J. Texture Stud. 28 (2) (1997) 221-237 https://doi.org/10.1111/j.1745-4603. 1997.tb00112.x.

[35] AACC International, Approved methods of analysis, Method 66-50.01. Pasta and Noodle Cooking Quality-Firmness, 11th ed., AACC International, St. Paul, U.S.A, 2000, , https://doi.org/10.1094/AACCIntMethod-66-50.01.

[36] R.C. Hoseney, J. Smewing, Instrumental measurement of stickiness of doughs and other foods, J. Texture Stud. 130 (2) (1999) 123-136, https://doi.org/10.1111/j. 1745-4603.1999.tb00206.x.

[37] O.H. Lowry, N.J. Rosebrough, A.L. Farr, R.J. Randall, Protein measurement with the Folin phenol reagent, J. Biol. Chem. 193 (1951) 265-275 http://www.jbc.org/ content/193/1/265.long.

[38] J.B. Marsh, D.B. Weinstein, Simple charring methods for determination of lipids, J. Lipid Res. 7 (1966) 574-576 http://www.jlr.org/content/7/4/574.long.

[39] M. Dubois, K.A. Gilles, J.K. Hamilton, P. Rebers, F. Smith, Colorimetric method for determination of sugars and related substances, Anal. Chem. 28 (3) (1956) 350-356 https://doi.org/10.1021/ac60111a017.

[40] S.T. Jeffrey, G.F. Humphrey, New spectrophotometric equations for determining chlorophylls a, b, c1 and c2 in higher plants, algae and natural phytoplankton, Biochem. Physiol. Pflanz. 167 (2) (1975) 191-194 https://doi.org/10.1016/S00153796(17)30778-3.

[41] P. Ganesan, C.S. Kumar, N. Bhaskar, Antioxidant properties of methanol extract and its solvent fractions obtained from selected Indian red seaweeds, Bioresour. Technol. 99 (2008) 2717-2723 https://doi.org/10.1016/j.biortech.2007.07.005.

[42] G. Rajauria, A.K. Jaiswal, N. Abu-Ghannam, S. Gupta, Antimicrobial, antioxidant and free radical-scavenging capacity of brown seaweed Himanthalia elongata from western coast of Ireland, J. Food Biochem. 37 (2013) 322-335, https://doi.org/10 1111/j.1745-4514.2012.00663.x.

[43] S. Boisen, J.A. Fernández, Prediction of the total tract digestibility of energy in feedstuffs and pig diets by in vitro analyses, Anim. Feed Sci. Technol. 68 (1997) 277-286 https://doi.org/10.1016/S0377-8401(97)00058-8.

[44] S.P. Fragoso, Desenvolvimento de bolachas com incorporação de diferentes microalgas, Master Thesis Instituto Superior de Agronomia, Universidade de Lisboa, Portugal, 2016https://www.repository.utl.pt/handle/10400.5/13367.

[45] F. Cabrera-Chávez, A.M.C. de la Barca, A.R. Islas-Rubio, A. Marti, M. Marengo, M.A. Pagani, F. Bonomi, S. Iametti, Molecular rearrangements in extrusion processes for the production of amaranth-enriched, gluten-free rice pasta, LWT Food Sci. Technol. 47 (2012) 421-426 https://doi.org/10.1016/j.lwt.2012.01.040.

[46] N. Zouari, M. Abid, N. Fakhfakh, M.A. Ayadi, L. Zorgui, M. Ayadi, H. Attia, Bluegreen algae (Arthrospira platensis) as an ingredient in pasta: free radical scavenging activity, sensory and cooking characteristics evaluation, Int. J. Food Sci. Nutr. 62 8) (2011) 811-813 https://doi.org/10.3109/09637486.2011.582461.

[47] G. Özyurt, L. Uslu, I. Yuvka, S. Gökdoğan, G. Atci, B. Ak, O. Ișik, Evaluation of the cooking quality characteristics of pasta enriched with Spirulina platensis, J. Food Qual. 38 (2015) 268-272 https://doi.org/10.1111/jfq.12142.

[48] M.R. Castellar, J.M. Obón, J.A. Fernández-López, The isolation and properties of a concentrated red-purple betacyanin food colorant from Opuntia stricta fruits, J. Sci. Food Agric. 86 (2006) 122-128 https://doi.org/10.1002/jsfa.2285.

[49] L.M. König, B. Renner, Colourful = healthy? Exploring meal colour variety and its relation to food consumption, Food Qual. Prefer. 64 (2018) 66-71 https://doi.org/ 10.1016/j.foodqual.2017.10.011

[50] B.A. Marchylo, J.E. Dexter, L.J. Malcolmson, Improving the texture of pasta, in: D. Kilcast (Ed.), Texture of Food, Woodhead Publishing, Ltd, Cambridge, 2004, pp. 475-500.
[51] V. Larrosa, G. Lorenzo, N. Zaritzky, A. Califano, Improvement of the texture and quality of cooked gluten-free pasta, LWT Food Sci. Technol. 70 (2016) 96-103 https://doi.org/10.1016/j.lwt.2016.02.039.

[52] A. Marti, A. Barbiroli, M. Marengo, L. Fongaro, S. Iametti, M.A. Pagani, Structuring and texturing gluten-free pasta: egg albumen or whey proteins? Eur. Food Res. Technol. 238 (2014) 217-224 https://doi.org/10.1007/s00217-013-2097-4.

[53] M.J. Sissons, N. Egan, M.C. Gianibelli, New insights into the role of gluten on durum pasta quality using reconstitution method, Cereal Chem. 82 (2005) 601-608 https://doi.org/10.1094/CC-82-0601.

[54] J.E. Dexter, R.R. Matsuo, A.W. MacGregor, Relationship of instrumental assessment of spaghetti cooking quality to the type and the amount of material rinsed from cooked spaghetti, J. Cereal Sci. 3 (1985) 39-53 https://doi.org/10.1016/S07335210(85)80032-1.

[55] A.S. Martinez, P.D. Ribotta, A.E. León, M.C. Añón, Physical, sensory and chemical evaluation of cooked spaghetti, J. Texture Stud. 38 (6) (2007) 666-683, https://doi. org/10.1111/j.1745-4603.2007.00119.

[56] H. Weiser, R. Kieffer, Correlations of the amount of gluten protein types to the technological properties of wheat flours determined on a micro-scale, J. Cereal Sci. 34 (2001) 19-27, https://doi.org/10.1006/jcrs.2000.0385.

[57] E.R. de Marco, M.E. Steffolani, C.S. Martínez, A.E. León, Effects of spirulina biomas on the technological and nutritional quality of bread wheat pasta, LWT Food Sci. Technol. 58 (2014) 102-108, https://doi.org/10.1016/j.lwt.2014.02.054.

[58] European Commission, Commission Regulation (EC) $N^{\circ}$ 629/2008 amending Regulation (EC) $\mathrm{N}^{\circ} 1881 / 2006$ setting maximum levels for certain contaminants in foodstuffs. Brussels, Off. J. Eur. Union 176 (2008) 6-9.

[59] G. Pounis, A. di Castelnuovo, S. Costanzo, M. Persichillo, M. Bonaccio, A. Bonanni, C. Cerletti, M.B. Donati, G. Gaetano, L. Iacoviello, Pasta consumption is negatively associated with obesity markers: an analysis of Moli-sani and INHES studies, FASEB J. 30 (1S) (2016) lb308 https://www.fasebj.org/doi/10.1096/fasebj.30.1_ supplement.lb308.

[60] E. Nouri, H. Abbasi, Effects of different processing methods on phytochemical compounds and antioxidant activity of Spirulina platensis, Appl. Food Biotechnol. 5 (4) (2018) 221-232, https://doi.org/10.22037/afb.v\%vi\%i.20715.

[61] K. Chopra, M. Bishnoi, Antioxidant profile of spirulina: a blue-green microalga, in: M.E. Gershwin, A. Belay (Eds.), Spirulina in Human Nutrition and Health, CRC Press, Boca Raton, 2008, pp. 101-118.

[62] M.M. Poojary, F.J. Barba, B. Aliakbarian, F. Donsì, G. Pataro, D.A. Dias, P. Juliano, Innovative alternative technologies to extract carotenoids from microalgae and seaweeds, Mar. Drugs 14 (11) (2016) 214 https://doi.org/10.3390/md14110214.

[63] L. Jespersen, L.D. Strømdahl, K. Olsen, L.H. Skibsted, Heat and light stability of three natural blue colorants for use in confectionery and beverages, Eur. Food Res. Technol. 220 (3-4) (2005) 261-266 https://doi.org/10.1007/s00217-004-1062-7.

[64] A. Alves-Rodrigues, A. Shao, The science behind lutein, Toxicol. Lett. 150 (2004) 57-83 https://doi.org/10.1016/j.toxlet.2003.10.031.

[65] V. da Silva Ferreira, C. Sant'Anna, Impact of culture conditions on the chlorophyll content of microalgae for biotechnological applications, World J. Microbiol. Biotechnol. 33 (1) (2017) 20, https://doi.org/10.1007/s11274-016-2181-6.

[66] H. El Gharras, Polyphenols: food sources, properties and applications-a review, Int. J. Food Sci. Technol. 44 (12) (2009) 2512-2518 https://doi.org/10.1111/j. 1365-2621.2009.02077.x.

[67] S.J. Hur, B.O. Lim, E.A. Decker, D.J. McClements, In vitro human digestion models for food applications, Food Chem. 125 (2011) 1-12 https://doi.org/10.1016/j. foodchem.2010.08.036.

[68] S. Susanna, P. Prabhasankar, A study on development of gluten free pasta and its biochemical and immunological validation, LWT Food Sci. Technol. 50 (2013) 613-621 https://doi.org/10.1016/j.lwt.2012.07.040.

[69] G.A. Annor, C. Tyl, M. Marcone, S. Ragaee, A. Marti, Why do millets have slower starch and protein digestibility than other cereals? Trends Food Sci. Technol. 66 (2017) 73-83 https://doi.org/10.1016/j.tifs.2017.05.012. 